\title{
Involvement of the PI3K/Akt/NF- $\kappa$ B Signaling Pathway in the Attenuation of Severe Acute Pancreatitis-Associated Acute Lung Injury by Sedum sarmentosum Bunge Extract
}

\author{
Yuepeng Jin, ${ }^{1}$ Lewei Liu, ${ }^{2}$ Bicheng Chen, ${ }^{3}$ Yongyu Bai, ${ }^{4}$ Fan Zhang, \\ Qiang Li, ${ }^{4}$ Chongqing Lv, ${ }^{5}$ Hongwei Sun, ${ }^{1}$ Junjian Li, ${ }^{1}$ Sadman Rubby, \\ Lihong Yang, ${ }^{1}$ Roland Andersson, ${ }^{6}$ and Mengtao Zhou ${ }^{1}$ \\ ${ }^{1}$ Department of Surgery, The First Affiliated Hospital, Wenzhou Medical University, Wenzhou, Zhejiang Province, China \\ ${ }^{2}$ YueQing Affiliated Hospital of Wenzhou Medical University, YueQing People's Hospital, Yueqing, Zhejiang Province, China \\ ${ }^{3}$ Zhejiang Provincial Top Key Discipline in Surgery, Wenzhou Key Laboratory of Surgery, Department of Surgery, \\ The First Affiliated Hospital, Wenzhou Medical University, Wenzhou, Zhejiang Province, China \\ ${ }^{4}$ Wenzhou Medical University, Wenzhou, Zhejiang Province, China \\ ${ }^{5}$ Shengli Oilfield Central Hospital, Dongying, Shandong Province, China \\ ${ }^{6}$ Department of Surgery, Clinical Sciences Lund, Lund University and Lund University Hospital, Sweden
}

Correspondence should be addressed to Mengtao Zhou; zhoumengtao@wmu.edu.cn

Received 21 July 2017; Revised 19 September 2017; Accepted 22 October 2017; Published 5 December 2017

Academic Editor: Fabrizio Montecucco

Copyright (C) 2017 Yuepeng Jin et al. This is an open access article distributed under the Creative Commons Attribution License, which permits unrestricted use, distribution, and reproduction in any medium, provided the original work is properly cited.

Sedum sarmentosum Bunge possesses excellent anti-inflammatory properties and was used in the treatment of inflammatory diseases. The aim of the present study was to investigate the efficiency of Sedum sarmentosum Bunge extract (SSBE) on severe acute pancreatitis-associated (SAP-associated) acute lung injury (ALI) in rats and to explore the underlying mechanisms. Here, we used a sodium taurocholate-induced SAP rat model to determine the role of SSBE in ALI. During the course of pancreatitis, the expressions of phosphorylated phosphoinositide 3-kinases (PI3K)/protein kinase B (Akt) and nuclear factor-kappa B (NF- $\kappa$ B) p65 in the lungs were upregulated. Meanwhile, a parallel increase in the levels of interleukin-1 $\beta$ (IL-1 $\beta$ ), interleukin-6 (IL-6), and tumor necrosis factor- $\alpha$ (TNF- $\alpha$ ) in the lungs was observed after the induction of SAP. Treatment with SSBE significantly reduced the expression of p-Akt and p-p65 in the lungs and attenuated the severity of SAP-associated ALI compared to the SAP group at $12 \mathrm{~h}$ and $24 \mathrm{~h}$. In summary, this study showed that SSBE has beneficial effects on SAP-associated ALI, probably through the PI3-K/Akt signaling pathways by suppressing the NF- $\kappa \mathrm{B}$ activities.

\section{Introduction}

Severe acute pancreatitis is a potentially lethal inflammatory disease with variable involvement of the peripancreatic organs, and/or remote organ systems, by developing a systemic inflammatory response syndrome (SIRS) [1-7]. Among the systemic complications, ALI is the most frequent and potentially the most serious and may occur in $15 \%$ to $55 \%$ of SAP cases, including both ALI and the acute respiratory distress syndrome (ARDS) [8-10]. The associated mortality rate in SAP has been reported to be from $10 \%$ and up, where respiratory dysfunction (ALI and ARDS) is what mostly contributes to early mortality (i.e., during the first week) $[5,8,11-14]$.

Although there are numerous factors involved in the development of SAP-associated ALI, inflammatory mediators have been reported to play a dominant role in the pathogenesis of SAP-associated ALI [7, 15]. Activation of inflammatory signaling pathways, such as PI3-K/Akt and $\mathrm{NF}-\kappa \mathrm{B}$, is involved as underlying molecular mechanisms in the development of ALI [7, 16-19]. The upstream regulator of NF- $\kappa \mathrm{B}$ involves PI3-K/Akt [16] signaling pathways. The underlying mechanisms of SAP-associated ALI are thus complex, which may explain the lack of specific pharmacological 
interventions, despite innumerous attempts over the years [14, 20-22].

Sedum sarmentosum Bunge is a perennial succulent herb frequently used in the treatment of inflammatory diseases in Oriental countries [23-25]. The complete genome of Sedum sarmentosum has been sequenced [26] and previous studies have revealed that Sedum sarmentosum Bunge possess anti-inflammatory, antiangiogenic, antinociceptive, and antifibrogenic properties [27-29]. Synthesis of monocyte and macrophage-mediated inflammatory factors can be decreased by Sedum sarmentosum Bunge [29]. Active chemical components in Sedum sarmentosum Bunge identified include megastigmane glycoside, quercetin, isorhamnetin, and kaempferide [27, 30]. Sedum sarmentosum possess antiinflammatory properties, and side effects seem to be limited [28]. In a previous preliminary study, we found antiinflammatory effects and an attenuation of the morphological injury in the lungs in a rat model of SAP [31].

The purpose of the present study was to verify whether SSBE attenuated the severity of SAP-associated ALI. If this was the case, we aimed at elucidating the underlying mechanisms explaining the effect of SSBE in ALI.

\section{Materials and Methods}

2.1. Animals. The Laboratory Animal Center of Wenzhou Medical University (Wenzhou, China) supplied 84 healthy male Sprague-Dawley (SD) rats (weighing 250-300 g, 10-12 weeks old). The rats were maintained under specific pathogen-free (SPF) conditions and the temperature was kept at $20-22^{\circ} \mathrm{C}$. A $12 \mathrm{~h}$ light-dark cycle was maintained, and all the rats were fed with a standard rat diet and water. All experiments were performed on animals after $12 \mathrm{~h}$ of fasting, but with free access to water.

2.2. Ethics Statement. The Institutional Animal Committee of Wenzhou Medical University, Wenzhou, China, approved the protocol for the animal experiment (Permit Number: wydw2013-0002). All animals received care in accordance with "Guide for the Care and Use of Laboratory Animals." All surgical interventions were performed under chloral hydrate anesthesia.

2.3. Animals and Groups. Eighty-four male SD rats were randomly divided into 3 groups: control group (control, $n=$ 28), SAP group (SAP, $n=28$ ), and SSBE treatment group (SSBE, $n=28$ ). Every group was divided into 4 subgroups, namely, $3,6,12$, and $24 \mathrm{~h}$ subgroups ( $n=7$ animals/group).

2.4. Materials. The following materials had been purchased from the sources as mentioned below: Sedum sarmentosum Bunge extract (Xuancheng Baicao Plant Industry and Trade Co., Ltd., Anhui, China); sodium taurocholate (Sigma Chemical Company, St Louis, MO, USA); Rat ELISA Kit for detecting IL- $1 \beta$, IL-6, and TNF- $\alpha$ (RapidBio Company, CA, USA); MPO Kit (JianCheng Biotechnology Research Institute, Nanjing, China); Akt and NF- $\kappa$ B p 65 and phosphorylated Akt and NF- $\kappa$ B p 65 antibodies (Cell Signaling Technology, Danvers, MA, USA); $\beta$-actin (Bioworld Technology, Louis Park, MN, USA).
2.5. The Animal Model for Induction of SAP. All procedures were performed in sterile conditions. The rats were anesthetized by subcutaneous injection of $10 \%$ chloral hydrate solution $(0.3 \mathrm{~mL} / 100 \mathrm{~g})$. According to Aho et al. [32], SAP was induced by retrograde injection of $5 \%$ sodium taurocholate $(1 \mathrm{ml} / \mathrm{kg})$ into the main pancreatic duct through a microinjection pump at a speed of $0.1 \mathrm{ml} / \mathrm{min}$. The control group had the same surgical procedure, but without the cannulation procedure and the retrograde injection of $5 \%$ sodium taurocholate.

2.6. Preparation and Administration of Sedum sarmentosum Bunge Extract. The extract protocol of Sedum sarmentosum Bunge has been shown by Bai et al. [29]. The whole plants were soaked in the tenfold distilled water for one hour and were used in the refluxing process of two hours. The extract was then filtrated and concentrated. Moreover, the drugs of the refluxing extract need further refluxing, filtration, and concentration. For animal experiments, $1 \mathrm{~g}$ of SSBE was dissolved in $10 \mathrm{ml}$ of normal saline, resulting in a concentration of $100 \mathrm{mg} / \mathrm{ml}$.

SSBE at a dose of $100 \mathrm{mg} / \mathrm{kg}$ was immediately administered subcutaneously and every $12 \mathrm{~h}$ following the establishment of the SAP model in the SSBE group. The 3, 6, and $12 \mathrm{~h}$ subgroups in the SSBE group were all administered with SSBE once. The $24 \mathrm{~h}$ subgroup in the SSBE group was administered with SSBE two times. Normal saline was administered in the same way as the other two groups.

2.7. Collection of Specimens. 3, 6, 12, and $24 \mathrm{~h}$ after the induction of SAP, seven rats from each group were randomly selected to undergo abdominal incision under anesthesia. Blood and pancreatic and lung tissues were collected for further analysis.

2.8. Histopathological Analysis. Tissues from the pancreas and lungs were harvested and fixed in $10 \%$ formaldehyde solution, embedded in paraffin, sectioned, and stained with hematoxylin-eosin (H\&E) for light microscopy. The pancreas pathological grading described by Schmidt et al. [33] was used, considering all factors, including edema, acinar necrosis, hemorrhage, fat necrosis, inflammation, and perivascular infiltration, when scoring the pancreatic injury in experimental SAP. Lung pathological scores were evaluated according to the method reported by Osman et al. [34]. An experienced pathologist examined the pathological sections unaware of the treatment groups, that is, in a blinded fashion.

2.9. Serum Amylase Activity and Levels of $I L-1 \beta$, IL-6, and TNF- $\alpha$ in Lung Tissue. Serum amylase activity was determined by means of iodine-amylum colorimetry and expressed in U/L. Lung tissue was homogenized and centrifuged, and the supernatants expressed in $\mathrm{pg} / \mathrm{ml}$ were collected to detect IL-1 $\beta$, IL- 6 , and TNF- $\alpha$ by means of enzymelinked immunosorbent assay (ELISA) using kits provided by the manufacturers.

2.10. Lung Wet/Dry Weight Ratio. The whole right lung of each rat was taken immediately after sacrifice, washed 
with PBS, and then weighed (wet weight). The tissues were dried for $72 \mathrm{~h}$ at $80^{\circ} \mathrm{C}$ in an electric oven and were then reweighed (dry weight). Tissue water content was determined by calculating the wet/dry weight ratio according to the formula: [water content $=$ (wet weight - dry weight $) /$ dry weight $\times 100 \%]$.

2.11. Lung MPO Activity. To carry out the assays, the supernatants of lung tissue were gathered after left lobectomy homogenization and centrifugation. Neutrophil sequestration within the lung was evaluated by quantitating tissue myeloperoxidase activity using a modification of the bromide-dependent chemiluminescence technique as described by Haqqani et al. [35].

2.12. Western Blot Analysis. For total cell extraction, tissue samples were homogenized in radio immunoprecipitation assay (RIPA) lysis buffer supplemented with protease inhibitor. The equal amounts of proteins were separated by $10 \%$ sodium dodecyl sulfate-polyacrylamide gel electrophoresis (SDS-PAGE) and transferred to a polyvinylidene difluoride (PVDF) membrane using transfer buffer at $350 \mathrm{~mA}$ for 70 minutes. Following the transfer of the protein, the membranes were blocked with 5\% skim milk in tris-buffered saline with Tween-20 (TBST) for $2 \mathrm{~h}$ at room temperature and then incubated with one of the following primary antibodies overnight at $4^{\circ} \mathrm{C}$ : p-Akt $(1: 1000)$, Akt $(1: 1000)$, NF- $\kappa \mathrm{B}$ p65 (1:1000), or $\beta$-actin $(1: 5000)$. The membranes were then washed 3 times in TBST and incubated with a secondary antibody for $1 \mathrm{~h}$ at room temperature. Subsequently, they were washed 3 times for $10 \mathrm{~min}$ in TBST, and target bands were developed using enhanced chemiluminescence (ECL) and exposed on films. Densitometry was measured using the QuantityOne Version of 4.6.2 Image Software (Bio-Rad).

2.13. Immunohistochemistry. Contiguous $4 \mu \mathrm{m}$ sections were cut from paraffin embedded lung tissue for immunohistochemistry. Sections were blocked with goat serum and immunostained after deparaffinization and rehydration. Sections were then incubated overnight with a 1/200 dilution of primary antibody against p-Akt and p-p65 at $4^{\circ} \mathrm{C}$, followed by incubation with secondary antibodies for $60 \mathrm{~min}$ at room temperature. The slides were developed with diaminobenzidine and counterstained with hematoxylin.

2.14. SSBE Side Effects Test. SSBE side effects were evaluated by checking serum alanine transaminase (ALT) and serum creatinine (Scr) levels in the liver and renal functions of male SD rats. Seven male SD rats were used as control (SSBE was not administered). Twenty-eight male SD rats were given SSBE subcutaneously at a dose of $100 \mathrm{mg} / \mathrm{kg}$ every $12 \mathrm{~h}$. Blood samples were drawn from the control group as well ( $0 \mathrm{~h}$ group). Blood samples after SSBE administration were collected at $3 \mathrm{~h}, 6 \mathrm{~h}, 12 \mathrm{~h}$, and $24 \mathrm{~h}$ after administration of SSBE. Serum ALT and serum Scr levels were determined using Beckman Coulter AU5821 automatic biochemistry analyzer (Beckman Coulter, Inc., Fullerton, CA, USA). The results were expressed in $\mathrm{U} / \mathrm{L}$ and $\mu \mathrm{mol} / \mathrm{L}$.
2.15. Statistical Analysis. Statistical Package for the Social Sciences (SPSS) software 18.0 (Chicago, IL, USA) was used to compute the mean \pm standard deviation. Statistical analysis was analyzed by the one-way analysis of variance (ANOVA) followed by SNK-q test as a post hoc test. For all analyses, statistical significance was defined as $p<0.05$.

\section{Results}

3.1. Morphological and Pathological Changes of Pancreas and Lungs. There were no morphological changes observed in the pancreas and lung tissue in the control group at any time points. Characteristic morphological features associated with acute pancreatitis, necrosis, calcic spots, hyperaemia, edema, color changes of the pancreas, and bloody ascitic fluid in the abdominal cavity were observed in the SAP group. In the SSBE group, calcic spots and bloody ascitic fluid in the abdominal cavity decreased significantly. Lung edema, local atelectasis, and pleural effusion were observed in the SAP group. These changes were relieved in the SSBE group at both 12 and $24 \mathrm{~h}$.

Pathological examination was normal in the control group. Under the microscope, acinar cell necrosis, cytoplasmic vacuolization, edema, inflammatory cell infiltration, and hemorrhage were observed in the pancreas from $3 \mathrm{~h}$ after induction, with increasing severity after 6,12 , and $24 \mathrm{~h}$. Alveolar wall thickening and infiltration of inflammatory cells in the lungs were shown from $3 \mathrm{~h}$ after pancreatitis induction and were aggravated at 6,12 , and $24 \mathrm{~h}$. Mild hemorrhage was noted in the lungs from $6 \mathrm{~h}$ after the induction of pancreatitis and was aggravated with time. These changes in the pancreas and lungs were alleviated in the SSBE group compared to the SAP group at both 12 and $24 \mathrm{~h}$ (Figures 1 and 2).

The pathological scores of the pancreas and lung tissue in the SSBE group were lower compared to the SAP group at 12 and $24 \mathrm{~h}(p<0.05$; Figure 3$)$.

3.2. Serum Amylase Activity and Lung Wet/Dry Weight Ratio. Serum amylase activity increased in the SAP group and the SSBE group following the induction of SAP. Serum amylase activity in the SSBE group was significantly lower than in the SAP group at 3, 6, 12, and $24 \mathrm{~h}(p<0.05$; Figure 4$)$.

Lung wet/dry weight ratio was manifested over time. It was reduced in the SSBE group compared to the SAP group at 12 and $24 \mathrm{~h}(p<0.05)$. A $3.62 \%$ of lung wet/dry weight ratio in the SAP group was shown after $24 \mathrm{~h}$ compared to $2.81 \%$ in the SSBE group $(p<0.05$; Figure 4$)$.

3.3. Lung MPO Activity and Levels of $I L-1 \beta, I L-6$, and TNF- $\alpha$ in Lung Tissue. Neutrophil sequestration in the lungs was quantified by measuring the lung MPO activity. As shown in Figure 5, sodium taurocholate-induced pancreatitis-associated ALI was associated with an increase in lung MPO activity at 3, 6, 12, and $24 \mathrm{~h}$. Increased lung MPO activity indicated that neutrophils were sequestered within the lungs. Treatment with SSBE decreased the lung MPO activity after the induction of pancreatitis at 12 and $24 \mathrm{~h}$ $(p<0.05$; Figure 5). 


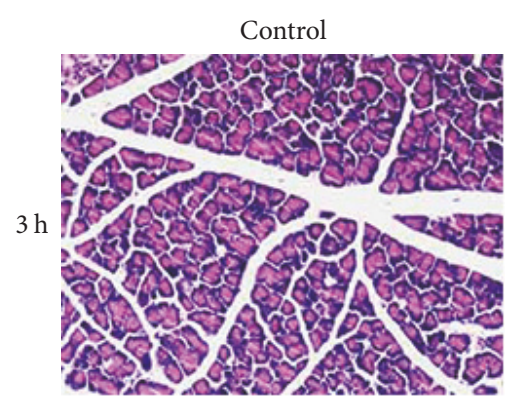

(a)

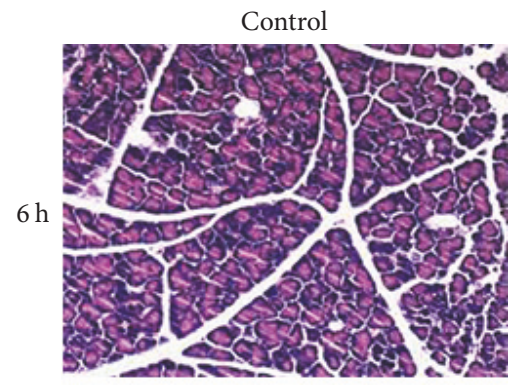

(d)

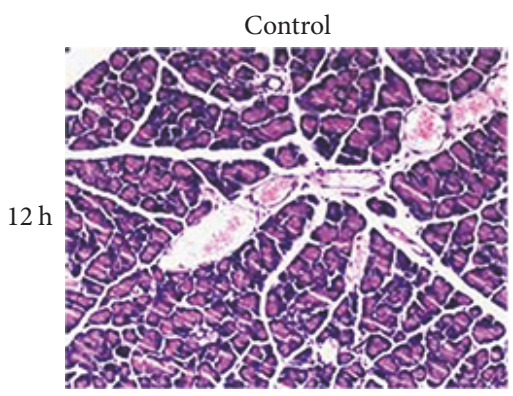

(g)

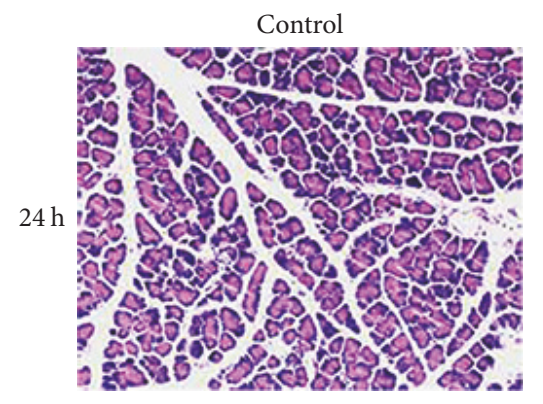

(j)

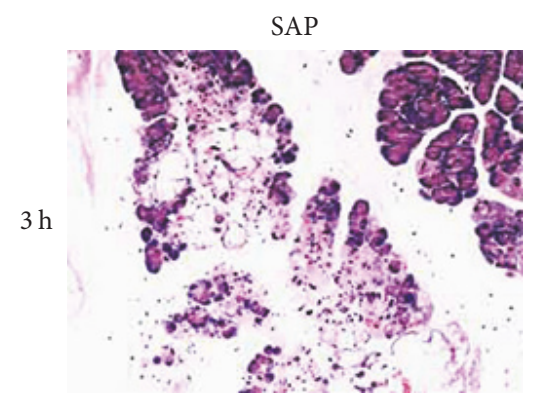

(b)

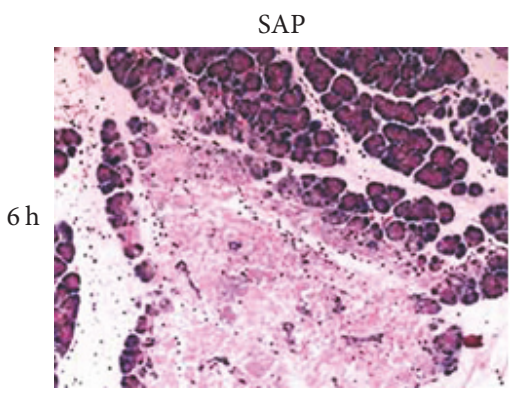

(e)

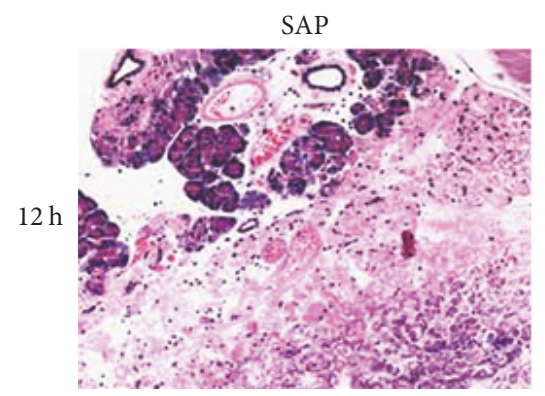

(h)

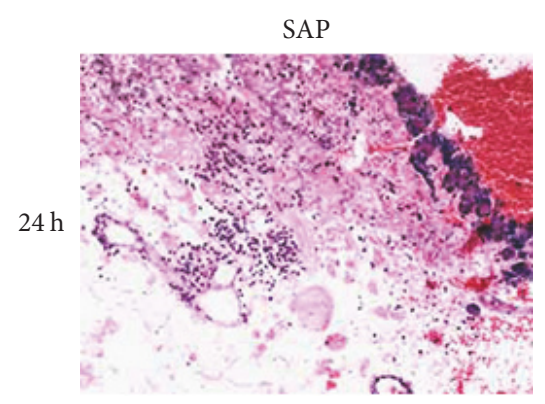

(k)

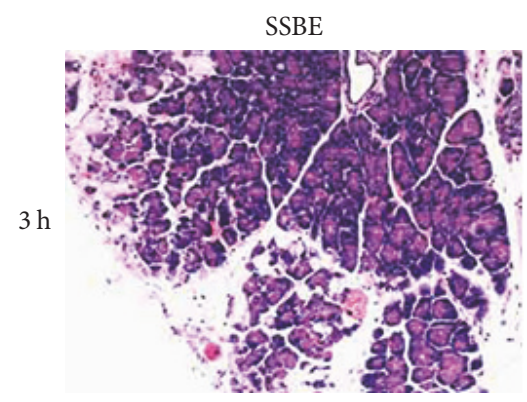

(c)

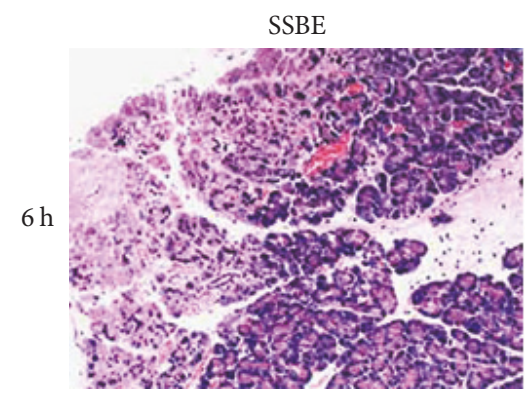

(f)

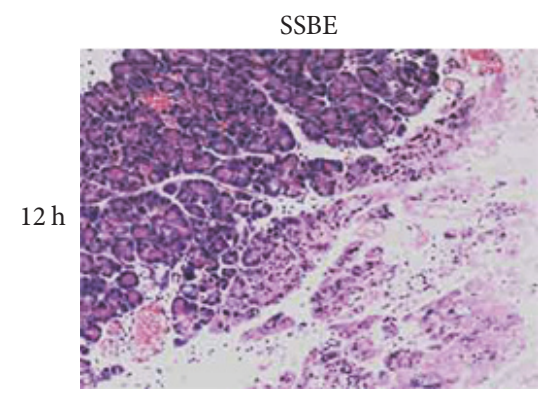

(i)

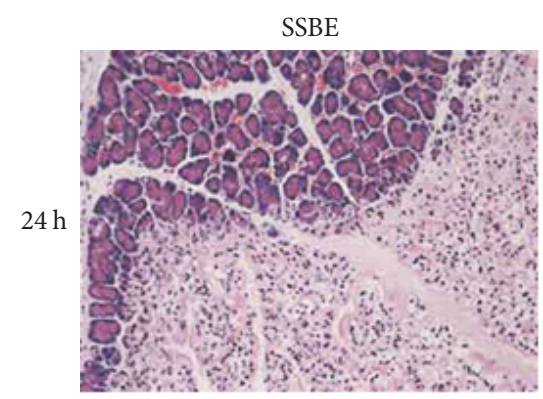

(1)

FIGURE 1: Histopathological analysis of the pancreas in SAP-associated ALI rats. Histopathological representation of the pancreas sections at different time points after sodium taurocholate induction of SAP. The representative haematoxylin-eosin stained sections of the pancreas at different time points from the control groups ( $a, d, g$, and j), the SAP groups (b, e, h, and k), and the SSBE groups (c, f, i, and l). Original magnification: $\times 100$.

To determine the expression of proinflammatory cytokines in the lungs, IL- $1 \beta$, IL- 6 , and TNF- $\alpha$ were evaluated. An increased expression of the proinflammatory cytokines IL-1 $\beta$, IL- 6 , and TNF- $\alpha$ in the lung tissue in the SAP group was seen as compared to the control group; though the expression of TNF- $\alpha$ did not significantly differ between the two groups at $3 \mathrm{~h}$. The peak expression of $\mathrm{L}-1 \beta$, IL- 6 , and TNF- $\alpha$ in the lung tissue occurred at $12 \mathrm{~h}$ after the induction of pancreatitis. In contrast, treatment with SSBE significantly reduced the production of L- $1 \beta$, IL- 6 , and 


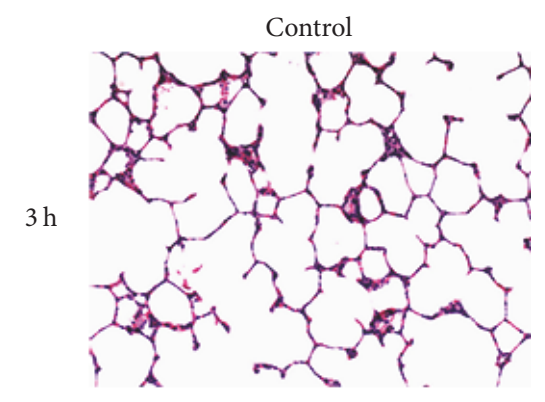

(a)

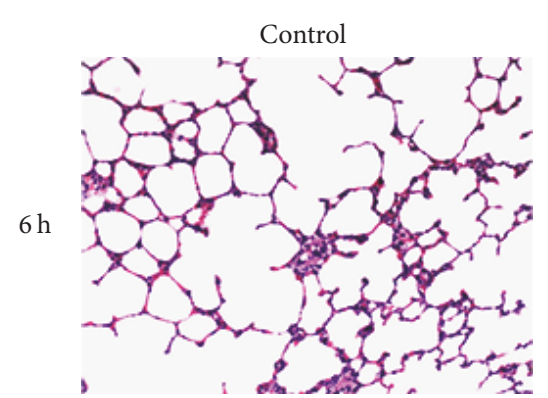

(d)

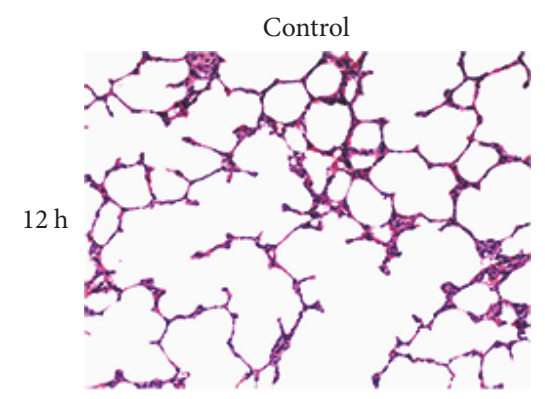

(g)

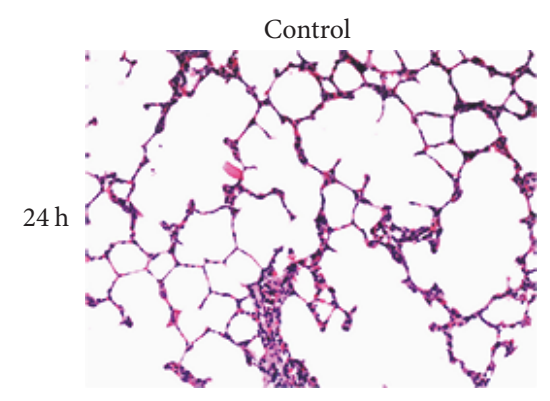

(j)

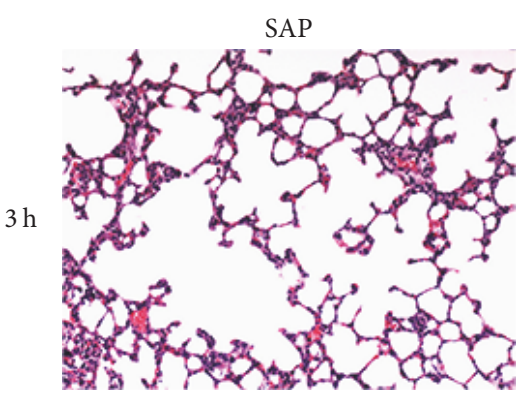

(b)

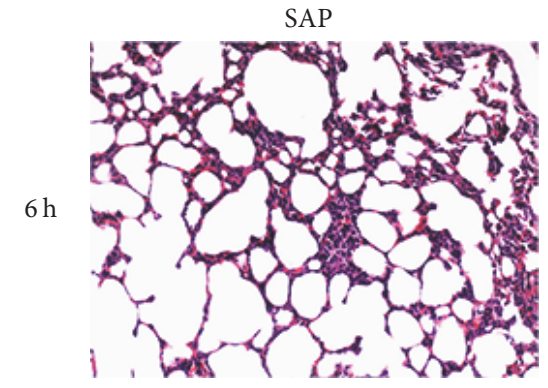

(e)

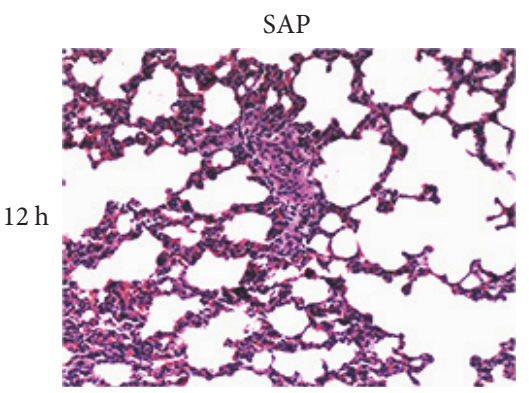

(h)

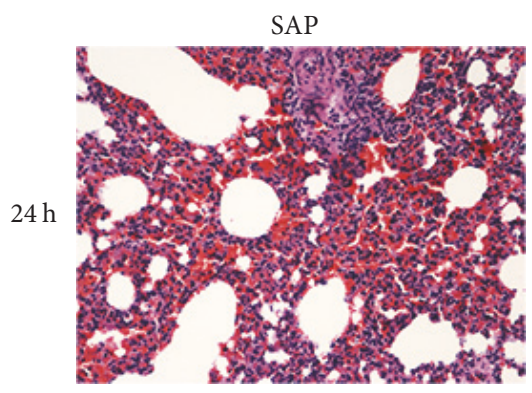

(k)

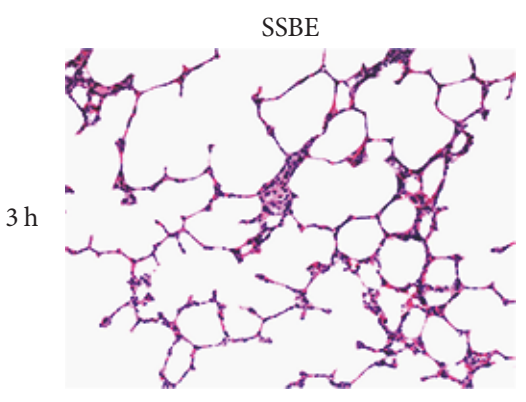

(c)

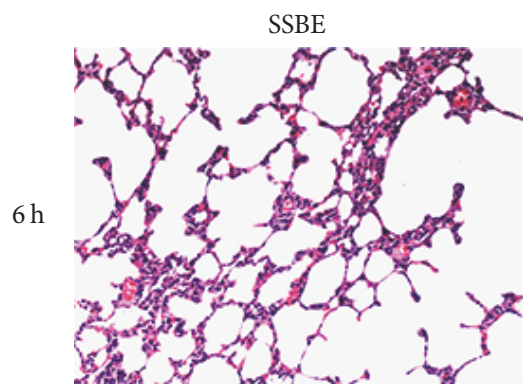

(f)

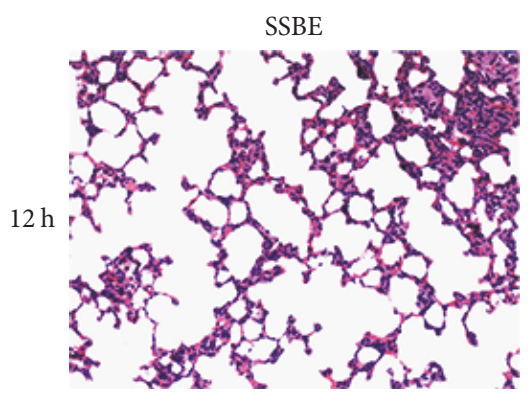

(i)

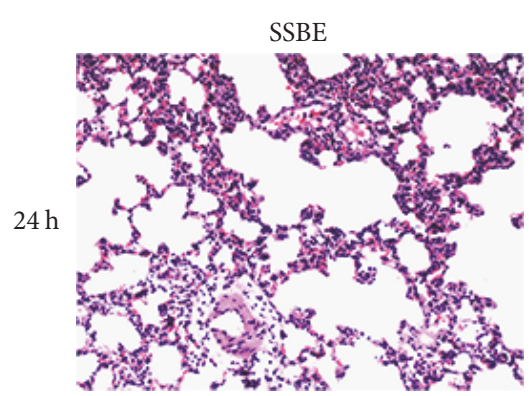

(l)

FIGURE 2: Histopathological analysis of the lungs in SAP-associated ALI rats. Histopathological representation of the lung sections at different time points after sodium taurocholate induction of SAP. The representative haematoxylin-eosin stained sections of the lung at different time points from the control groups ( $a, d, g$, and $j$ ), the SAP groups (b, e, h, and k), and the SSBE groups (c, f, i, and l). Original magnification: $\times 100$.

TNF- $\alpha$ at 12 and $24 \mathrm{~h}(p<0.05$; Figure 5). However, the levels of IL-1 $\beta$, IL- 6 , and TNF- $\alpha$ in the lung tissue did not significantly differ between the SAP group and the SSBE group at 3 and $6 \mathrm{~h}(p>0.05)$. These data indicate that SSBE decreased the expression of proinflammatory cytokines in the lungs and the onset time of SSBE was probably after $12 \mathrm{~h}$.
3.4. Expression of $p$-Akt/Akt Protein in the Lung Tissue. The protein expression of $\mathrm{p}$-Akt/Akt in the lung tissue was detected by Western blot analysis in our study. The protein expression of $\mathrm{p}$-Akt in the SAP group increased significantly at the 6,12 , and $24 \mathrm{~h}$ time points compared to the control group. Treatment with SSBE decreased the protein expression 


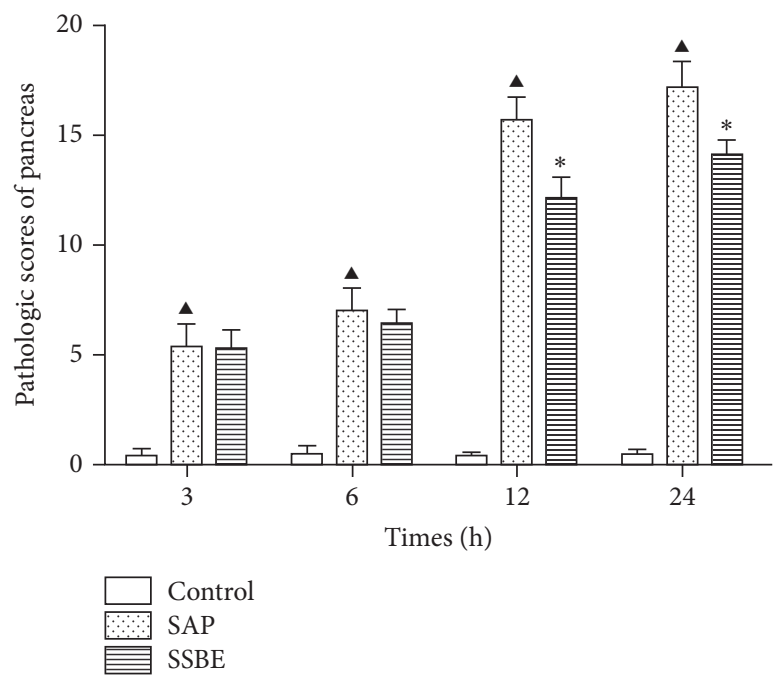

(a)
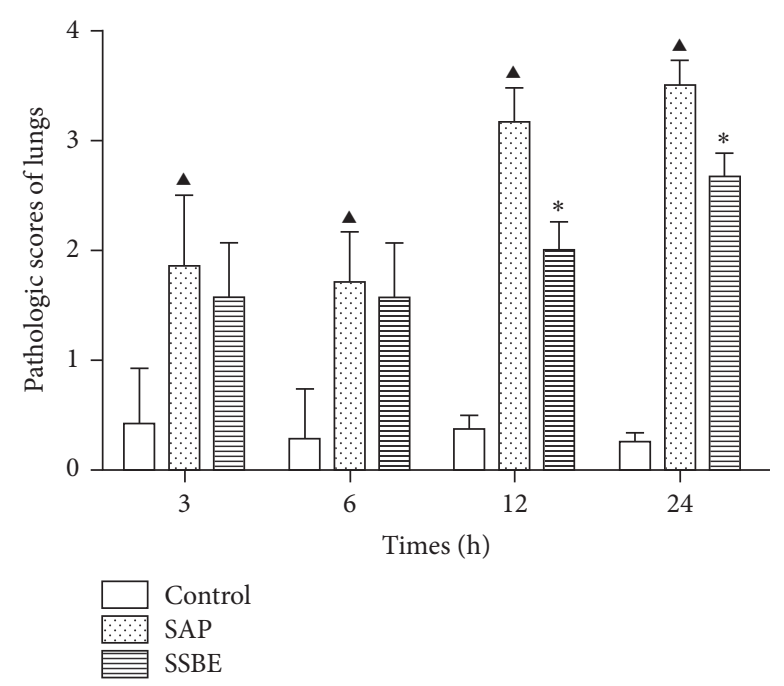

SBE

FIGURE 3: SSBE improved the pathological scores of the pancreas and lungs. The scores of the pancreas and lungs in the SSBE group were significantly lower compared to the SAP group at 12 and $24 \mathrm{~h} .\left({ }^{\boldsymbol{\Delta}} p<0.05 \mathrm{SAP}\right.$ group versus control group; ${ }^{*} p<0.05 \mathrm{SSBE}$ group versus SAP group.)

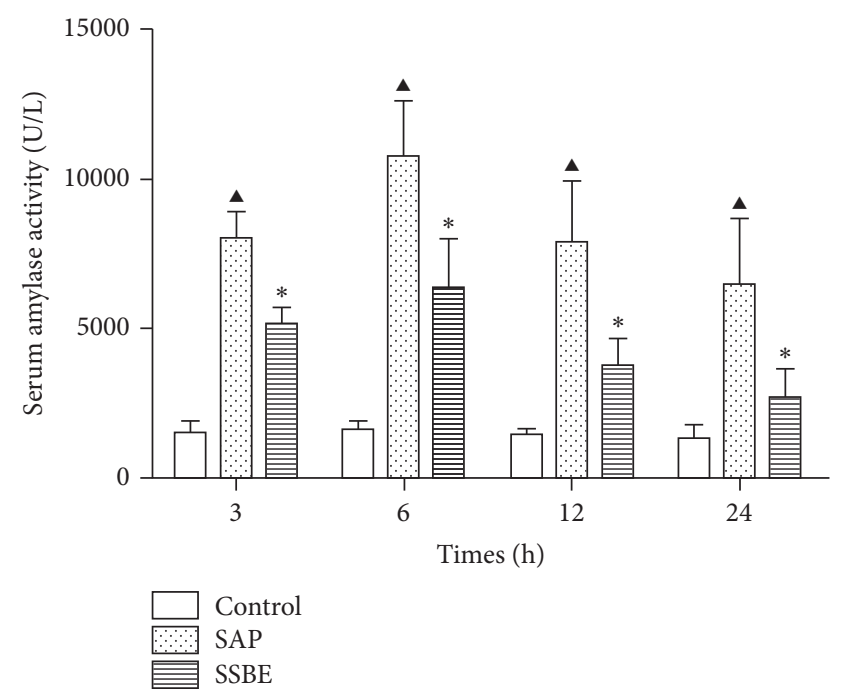

(a)

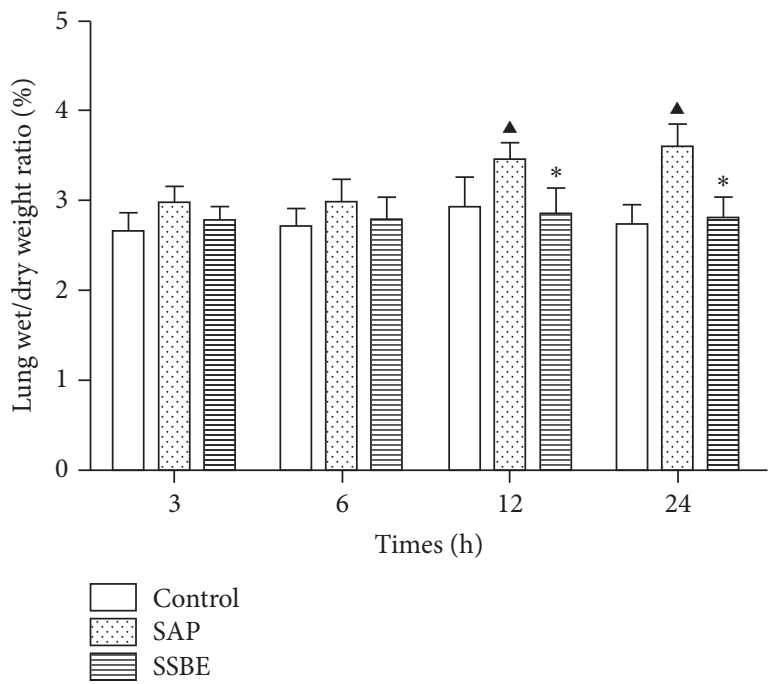

(b)

FIGURE 4: Serum amylase activity and lung wet/dry weight ratio. The SSBE group had lower levels of serum amylase at all four time points as compared to the SAP group. The lung wet/dry weight ratio in the SSBE group was lower as compared to the SAP group at 12 and $24 \mathrm{~h}$. $\left({ }^{\star} p<0.05\right.$ SAP group versus control group; ${ }^{*} p<0.05$ SSBE group versus SAP group.)

of p-Akt in the lung tissue at 12 and $24 \mathrm{~h}(p<0.05)$ but did not decrease at 3 and $6 \mathrm{~h}(p>0.05)$ (Figure 6). Furthermore, immunohistochemistry of p-Akt expression yielded similar results to Western bolt analysis (Figure 7).

3.5. Expression of NF- $\kappa B$ p-p65 in the Lung Tissue. Immunohistochemistry was performed to detect the expression of NF- $\kappa \mathrm{B}$ p-p65 in the lung tissue in each group. A negative expression of NF- $\kappa \mathrm{B}$ p-p65 was observed in the lung tissue in the control group at all time points. A weak positive expression in the SAP group was seen at 3 and $6 \mathrm{~h}$, with increasing positive expression after 12 and $24 \mathrm{~h}$. Treatment with SSBE decreased the expression of NF- $\kappa \mathrm{B}$ p-p65 in the lung tissue at 12 and $24 \mathrm{~h}$. The expression of NF- $\kappa \mathrm{B}$ p-p65 in the lung tissue was similar between the SAP and SSBE groups at 3 and $6 \mathrm{~h}$ (Figure 8).

Furthermore, Western blot analysis was used to investigate the expression of NF- $\kappa \mathrm{B}$ p-p65 in the lung tissue. As shown in Figure 6, the expression of NF- $\kappa$ B p-p65 significantly increased in the SAP group at 12 and $24 \mathrm{~h}$ compared 
TABLE 1: Serum alanine transaminase (ALT) and serum creatinine (Scr) levels after administering SSBE at different time points.

\begin{tabular}{lccccc}
\hline & $0 \mathrm{~h}($ control $)$ & $3 \mathrm{~h}$ & $6 \mathrm{~h}$ & $12 \mathrm{~h}$ & $24 \mathrm{~h}$ \\
\hline ALT $(\mathrm{U} / \mathrm{L})$ & $57.00 \pm 2.51$ & $57.14 \pm 1.95$ & $59.14 \pm 9.10$ & $54.14 \pm 6.54$ & $55.71 \pm 7.32$ \\
Scr $(\mu \mathrm{mol} / \mathrm{L})$ & $37.29 \pm 3.99$ & $35.43 \pm 4.31$ & $37.86 \pm 3.13$ & $36.14 \pm 6.04$ & $37.14 \pm 5.46$ \\
\hline
\end{tabular}

Seven male SD rats were used as control (SSBE was not administered). Twenty-eight male SD rats were given SSBE subcutaneously at a dose of $100 \mathrm{mg} / \mathrm{kg}$ every $12 \mathrm{~h}$. Blood samples were also drawn from the control group ( $0 \mathrm{~h}$ group). Blood samples after SSBE administration were collected at $3 \mathrm{~h}, 6 \mathrm{~h}, 12 \mathrm{~h}$, and $24 \mathrm{~h}$ after administration of SSBE.

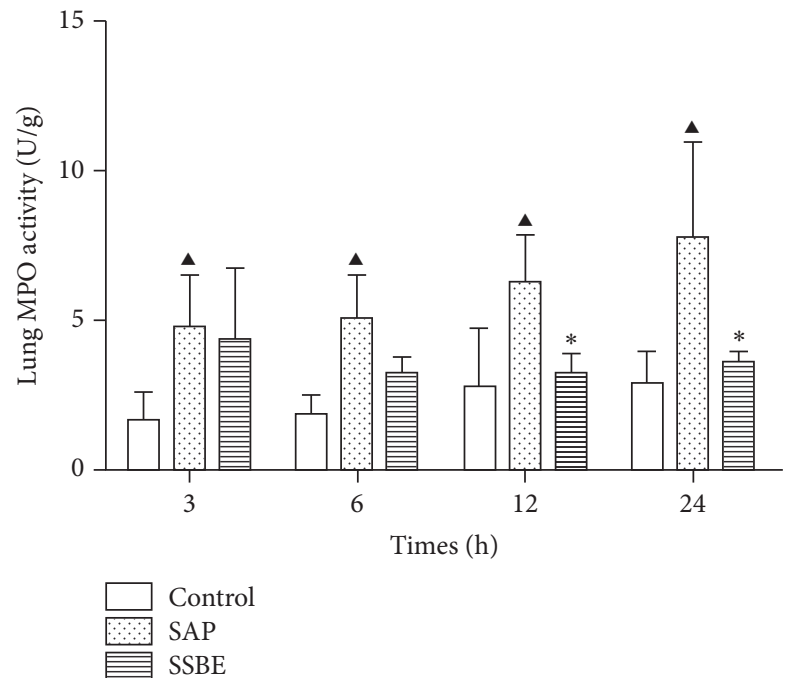

(a)

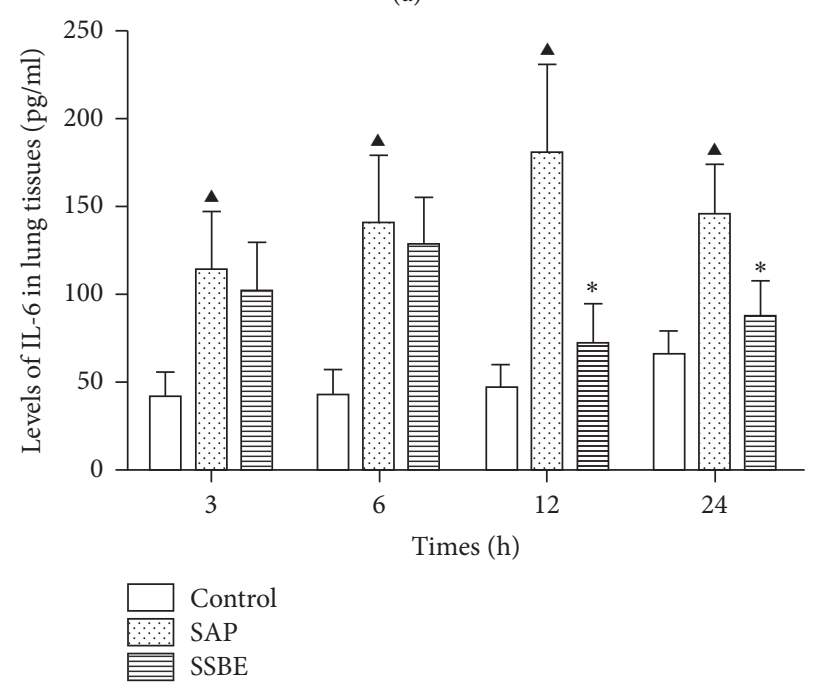

(c)
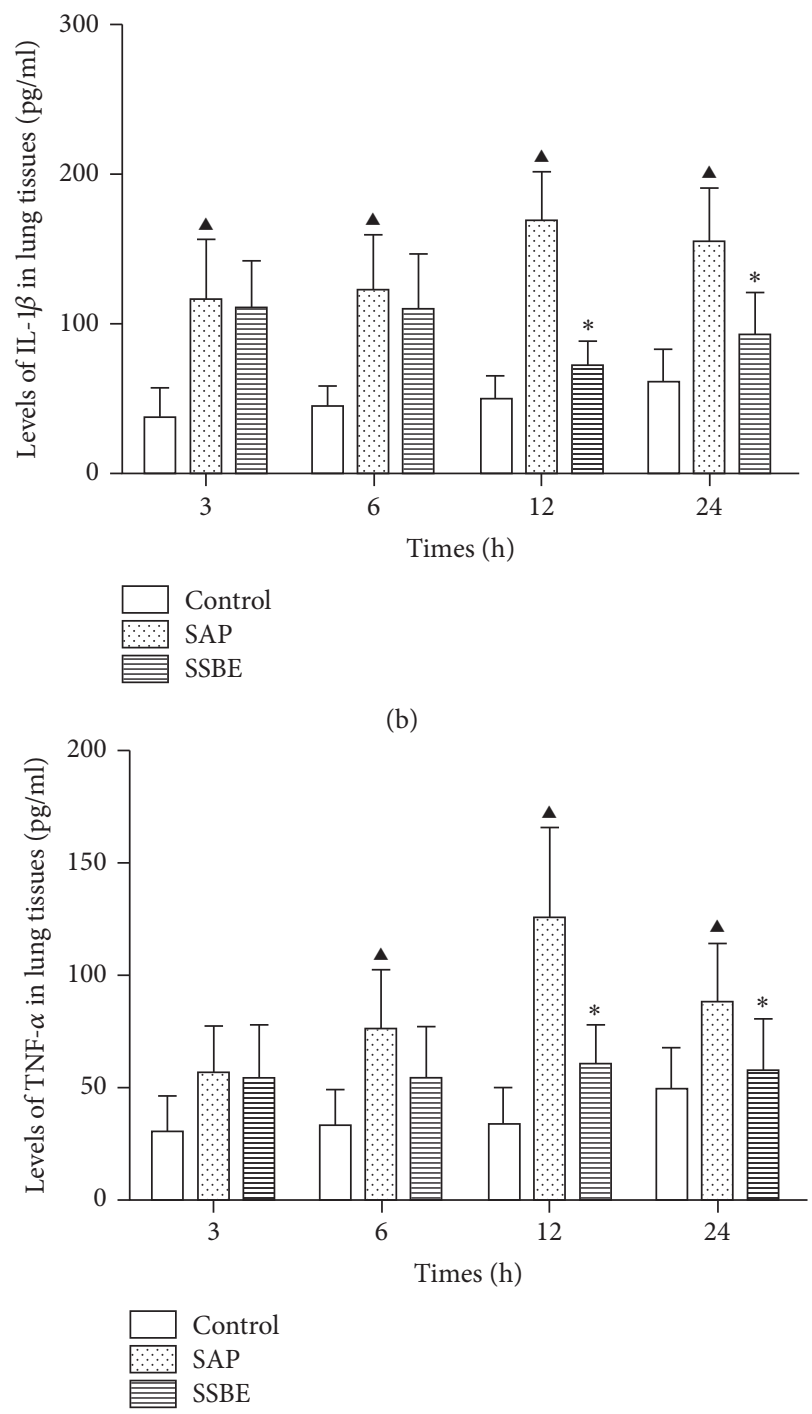

(b)

(d)

FIGURE 5: Lung MPO activity and levels of IL-1 $\beta, I L-6$, and TNF- $\alpha$ in the lung tissue. The SSBE group had a lower lung MPO activity and levels of IL-1 $\beta$, IL-6, and TNF- $\alpha$ in the lung tissue at 12 and $24 \mathrm{~h}$ time points as compared to the SAP group. No significant changes of lung MPO activity, IL-1 $\beta$, IL-6, and TNF- $\alpha$ in lung tissue were found in the control group. $\left({ }^{\boldsymbol{}} p<0.05\right.$ SAP group versus control group; ${ }^{*} p<0.05 \mathrm{SSBE}$ group versus SAP group.)

to the control group, while treatment with SSBE resulted in decreased protein expression of $\mathrm{p}-\mathrm{p} 65$ at 12 and $24 \mathrm{~h}(p<$ $0.05)$.

3.6. The Mortality Rate and Side Effects. The mortality rate in this research was zero. At a dose of $100 \mathrm{mg} / \mathrm{kg} \mathrm{q} 12 \mathrm{~h}$ there were no side effects observed as shown in Table 1.

\section{Discussion}

Previous pharmacological studies have shown that SSBE possesses excellent anti-inflammatory properties [27-29]. However, the effects of SSBE in experimental SAP-associated ALI have not been elucidated. Understanding the mechanisms underlying SSBE anti-inflammatory properties would 

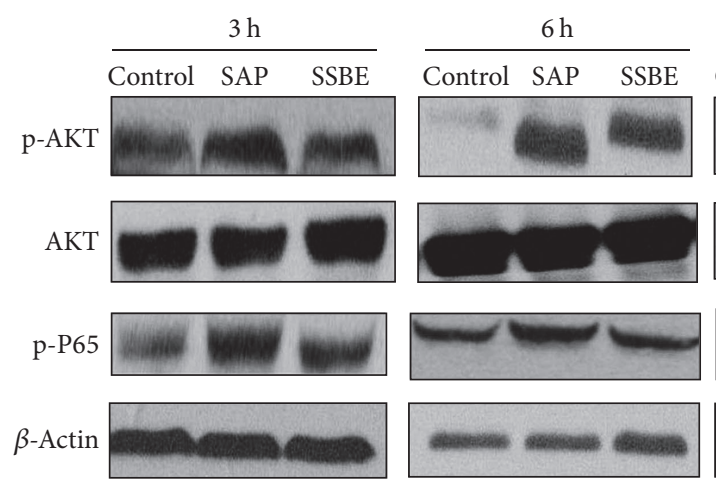

(a)
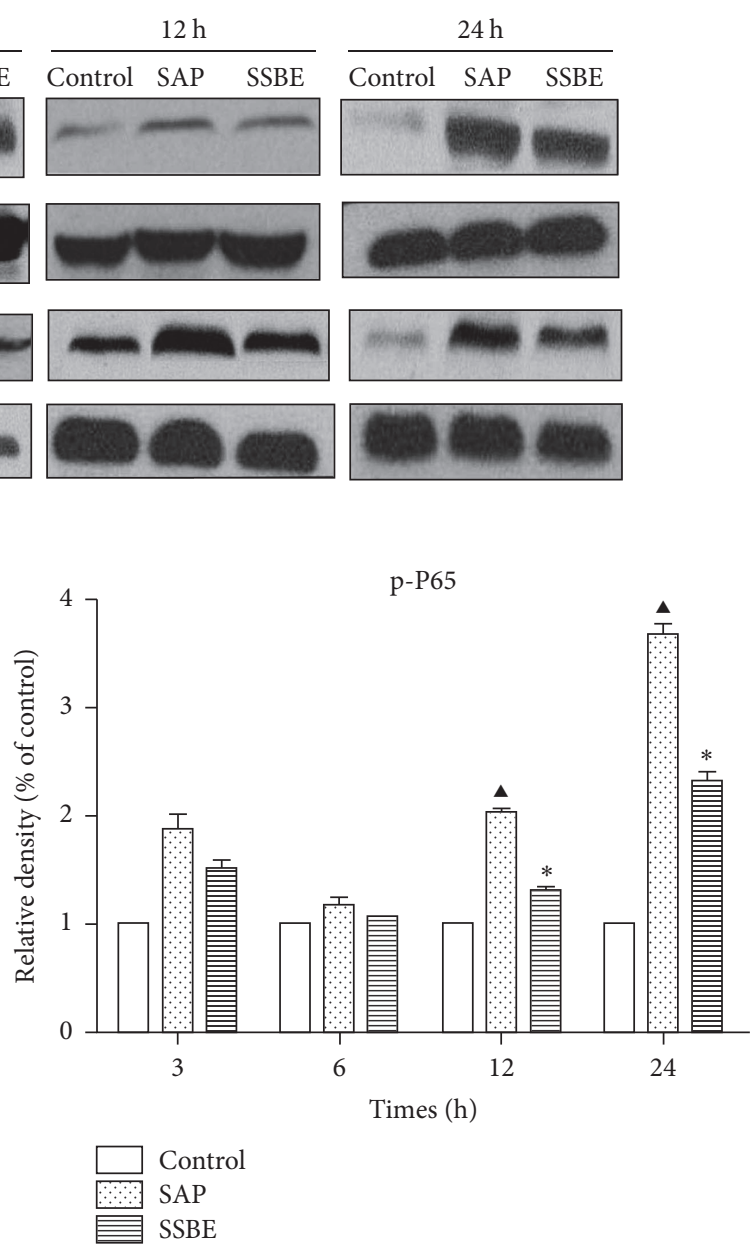

(b)

FiguRE 6: Western blot analysis of p-Akt/Akt and p-p65 protein levels in lungs at time points indicated. (a) Western blot results and (b) densitometric measurements. (a) Western blot analysis of the protein expression of p-Akt and p-p65 in lung tissue at different time points in the control group, the SAP group, and the SSBE group. (b) The graph shows densitometric measurements of Western blot. Activation of Akt was shown as the relative ratio between phosphorylated and total kinase. Activation of p65 was shown as the relative ratio of p-p65 to $\beta$-actin. ( ${ }^{\boldsymbol{\Delta}} p<0.05 \mathrm{SAP}$ group versus control group; ${ }^{*} p<0.05 \mathrm{SSBE}$ group versus SAP group.)

help to improve both understanding and the potential development of therapies directed towards SAP-associated ALI. PI3K/Akt and NF- $\kappa$ B are downstream inflammatory signaling pathways, which seem involved in the development of ALI [7, 16-19]. In the present study, we found that SSBE downregulated the activation of Akt and NF- $\kappa$ B p 65 in the lungs, contributing to the decrease of proinflammatory cytokines in sodium taurocholate-induced ALI rats model at later stages (12 and $24 \mathrm{~h}$ ).

Acute lung injury is the most pertinent manifestation of extra-abdominal organ dysfunction in SAP, not at least an important cause of especially early (the first week) mortality during the course of SAP [36]. It is considered that high concentrations of inflammatory mediators and activation of inflammatory cells play an important role in the initiation and progression of ALI $[7,15,37]$. The inflammatory mediators augment the inflammatory response, which stimulate the inflammatory cascade, leading to the systemic complications of acute pancreatitis. As a result, they cause the systemic inflammatory response syndrome (SIRS), acute respiratory distress syndrome (ARDS), and the multiple organ dysfunction syndrome (MODS). However, effective therapies for preventing development of ALI in pancreatitis are still lacking. Therefore, there is an urgent need for a potential beneficial pharmacological intervention.

In this study, SAP-associated ALI was induced by sodium taurocholate. Lung injury was proven, showing pulmonary inflammatory cell infiltration and alveolar wall thickening, as has been previously also demonstrated [31]. Sequestration of inflammatory cells, particularly neutrophils, within the lungs contributes to the development and severity of pancreatitis-associated lung injury [38]. MPO accounts for $3-5 \%$ of the total neutrophil proteins, making it the dominant neutrophil oxidant-generating system. Our results showed that the lung MPO activity was markedly upregulated during SAP-associated ALI. This is the most likely explanation for 


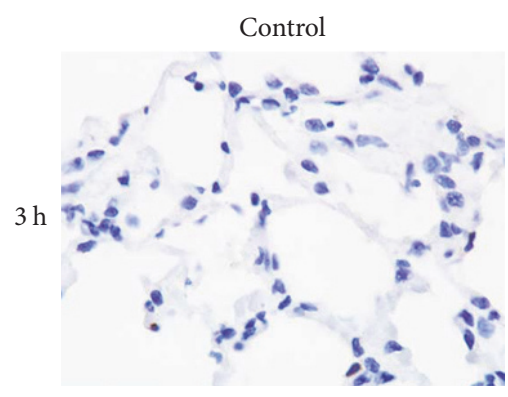

(a)

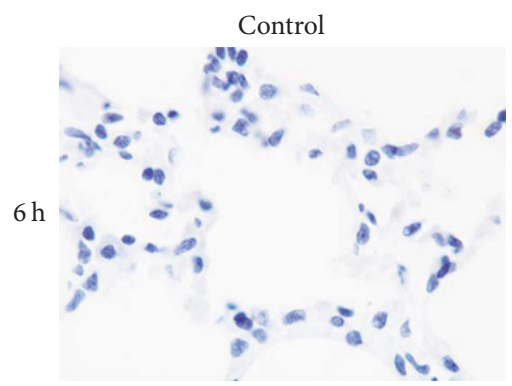

(d)

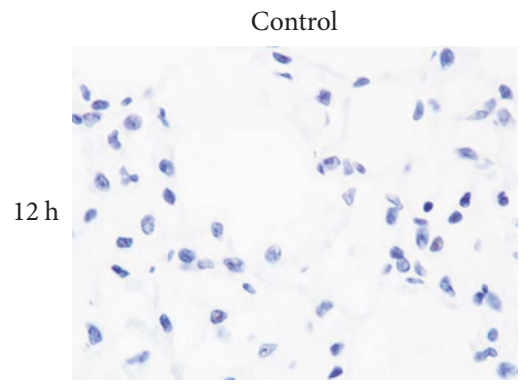

(g)

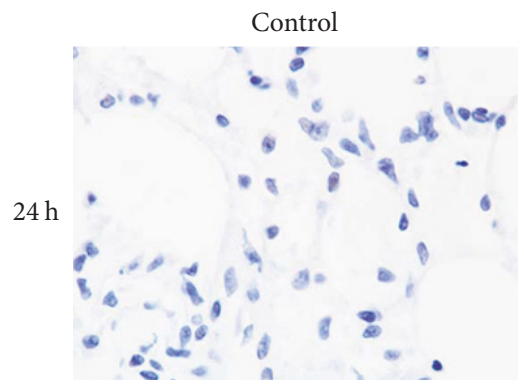

(j)

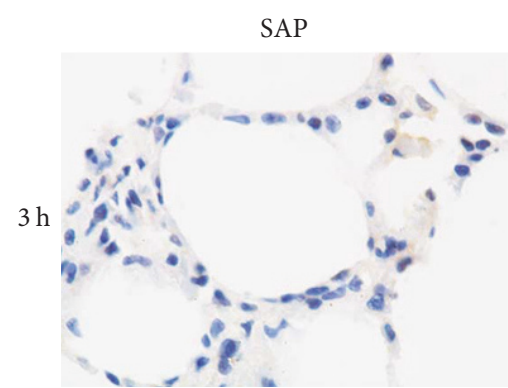

(b)

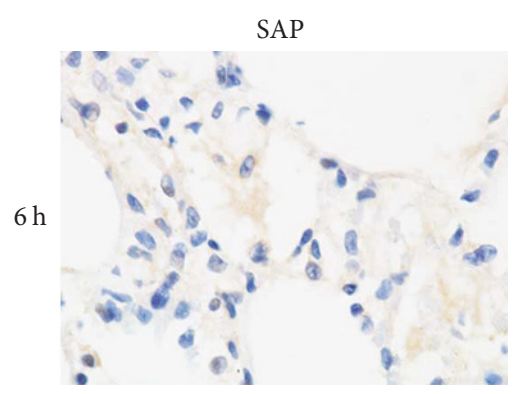

(e)

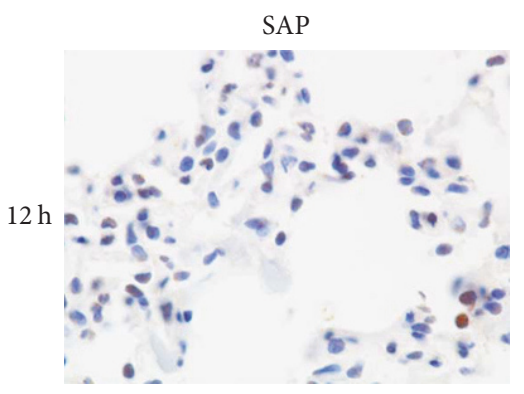

(h)

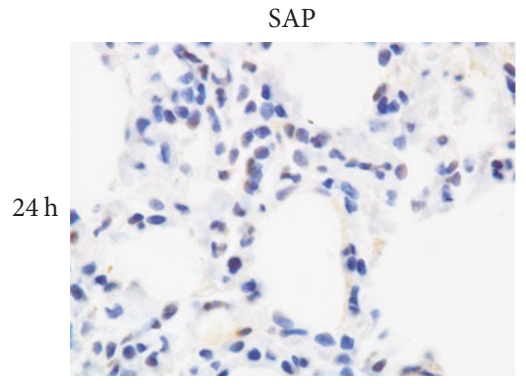

(k)

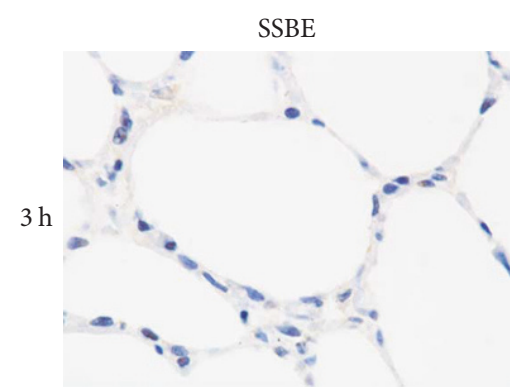

(c)

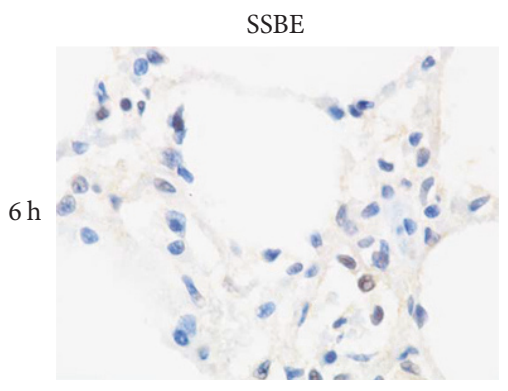

(f)

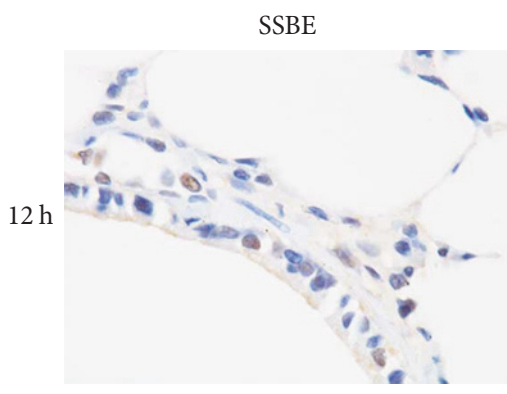

(i)

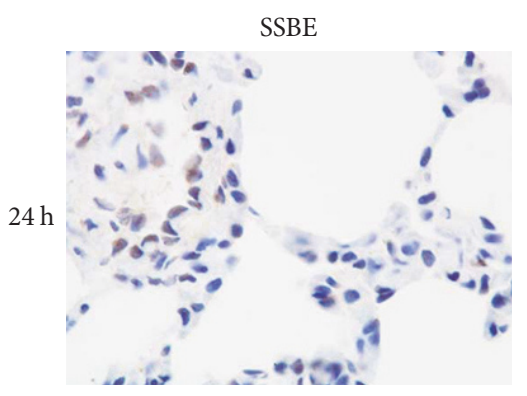

(l)

FIGURE 7: Immunohistochemical staining for p-Akt proteins expression in the lungs. Positive cells were stained dark brown. The control groups ( $a, d, g$, and $j$ ): negative expression in the control groups at different time points. The SAP groups (b, e, h, and k): weak positive expression at $3 \mathrm{~h}$ and $6 \mathrm{~h}$ and strong positive expression in the SAP groups at 12 and $24 \mathrm{~h}$. The SSBE groups (c, f, i, and l): positive expression at 12 and $24 \mathrm{~h}$ and weaker positive expression in the SSBE group compared to the SAP group at 12 and $24 \mathrm{~h}$. Weak positive expression at 3 and $6 \mathrm{~h}$, which was similar to the SAP groups at the same time points. Original magnification: $\times 1000$.

the neutrophil sequestration in the lungs. The neutrophils present in the lungs during ALI produce cytokines, resulting in an increased expression of proinflammatory cytokines, including IL-1 $\beta$, IL- 6 , and TNF- $\alpha$ in the lungs. The neutrophil infiltration and the increased levels of proinflammatory cytokines in the lungs aggravated the ALI. The currently available data concerning the model of SAP-associated ALI, including the increased pulmonary inflammatory cell infiltration, and alveolar wall thickening, coupled with the elevation of proinflammatory cytokines, was indicative of the development of ALI after sodium taurocholate induction [39-41]. Treatment with SSBE as demonstrated in the present 


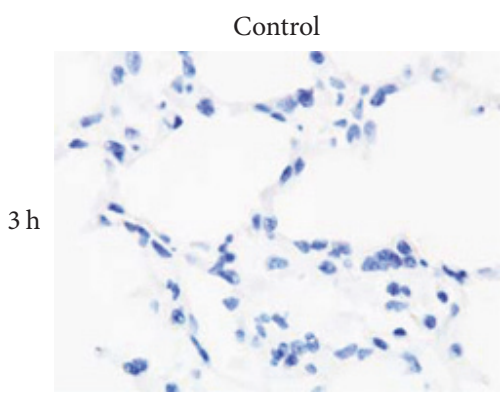

(a)

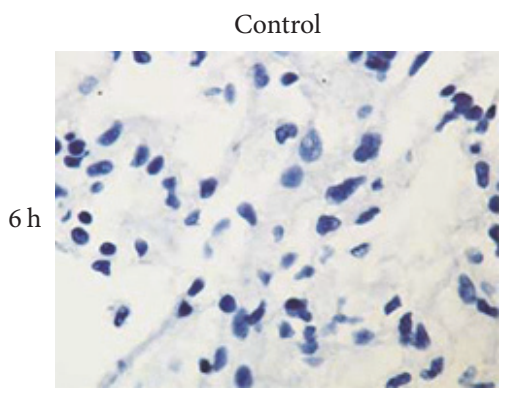

(d)

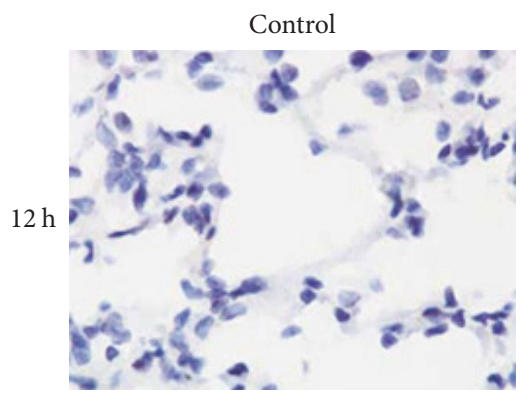

(g)

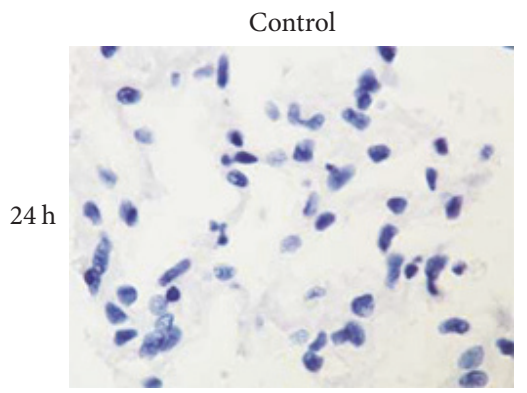

(j)

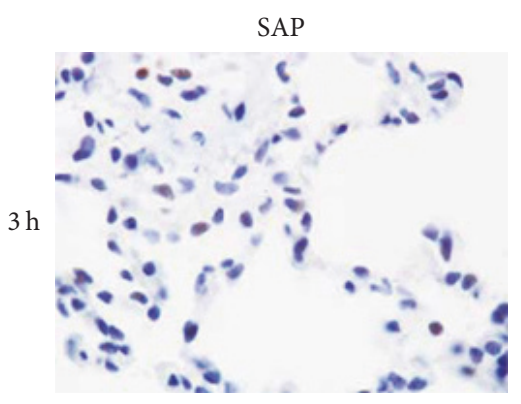

(b)

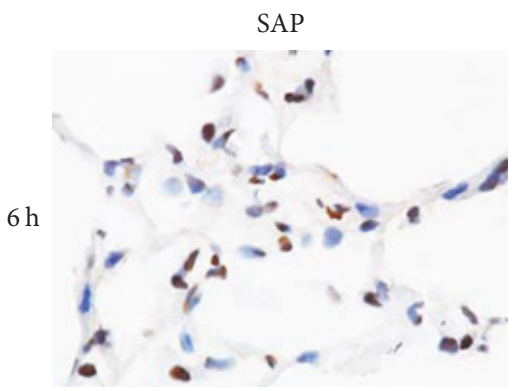

(e)

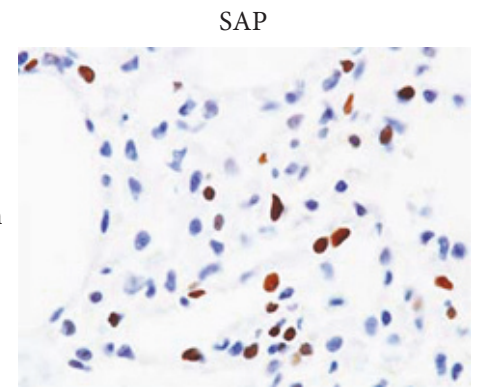

(h)

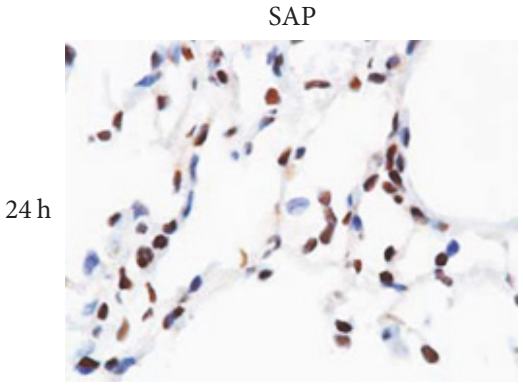

(k)

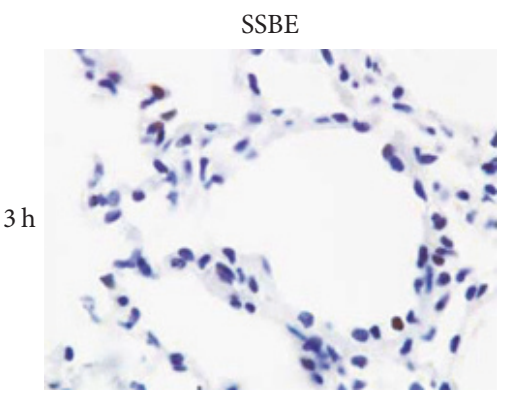

(c)

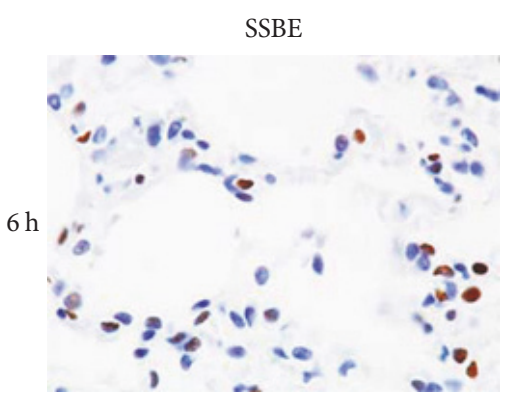

(f)

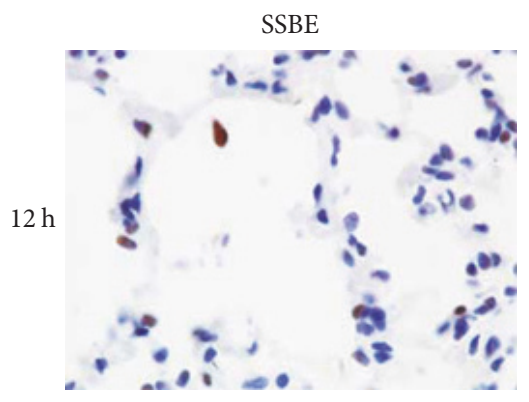

(i)

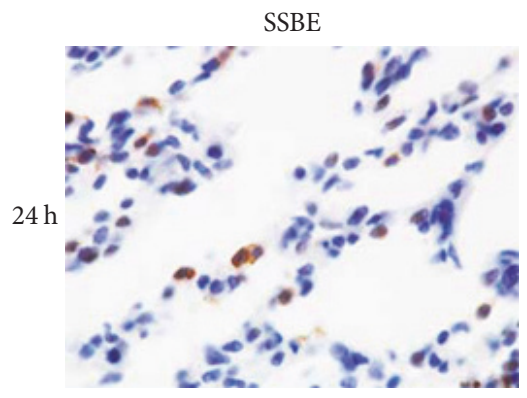

(1)

FIGURE 8: Immunohistochemical staining for p-p65 proteins expression in the lungs. Positive cells were stained dark brown. The control groups (a, d, g, and j): negative expression in the control groups at different time points. The SAP groups (b, e, h, and k): weak positive expression at $3 \mathrm{~h}$ and $6 \mathrm{~h}$ and strong positive expression in the SAP groups at 12 and $24 \mathrm{~h}$. The SSBE groups (c, f, i, and l): positive expression at 12 and $24 \mathrm{~h}$ and weaker positive expression in the SSBE group compared to the SAP group at 12 and $24 \mathrm{~h}$. Weak positive expression at 3 and $6 \mathrm{~h}$, which was similar to the SAP groups at the same time points. Original magnification: $\times 1000$.

study attenuated the pathological pulmonary injury scores, the wet/dry weight ratio, MPO activity, and proinflammatory cytokines in the lungs, indicating that SSBE reduced the severity of sodium taurocholate-induced lung injury. However, it was noticed that the effect of SSBE in SAP-associated
ALI was gradually increasing, with a peak at about $12 \mathrm{~h}$ after induction.

Several reports have demonstrated that PI3-K/Akt and NF- $\kappa \mathrm{B}$ signaling pathways participate in the regulation of inflammatory mediators, thus leading to acute lung injury 
$[16,42-45]$. In order to improve insights in the underlying mechanisms of SSBE in experimental ALI, we measured the levels of phosphorylated Akt and NF- $\kappa \mathrm{B}$ p65 in the lungs. Previous studies have shown that PI3-K, via the activation of Akt, can lead to an increase of the nuclear translocation and transcriptional activity of NF- $\kappa \mathrm{B}[16,46-48]$, which has a critical role in regulating the expression of cytokines, as well as the proinflammatory mediators involved in ALI. Its activation has a key influence on the pathogenesis of SAP [49], and, hence, inhibition of NF- $\kappa$ B can improve the survival of rats with pancreatitis [50]. Activation of Akt and NF- $\kappa \mathrm{B}$ p 65 in the lungs was measured by Western blot analysis and immunohistochemistry methods after induction of pancreatitis. Meanwhile, a parallel increase in the levels of proinflammatory cytokines (IL- $1 \beta$, IL- 6 , and TNF- $\alpha$ ) in the lungs was observed after the induction of SAP. These finding may indicate that Akt and NF- $\kappa \mathrm{B}$ signaling pathways probably have been activated during the early stage of pancreatitisassociated lung injury, leading to the release of proinflammatory cytokines. Our results showed that treatment with SSBE can downregulate the expression of phosphorylated Akt and NF- $\kappa \mathrm{B}$ p65 in the lungs at later stages (12 and $24 \mathrm{~h}$ ), contributing to the decrease of proinflammatory cytokines. Combined with previous reports, supporting our findings, it is implied that the underlying mechanisms of SSBE in SAPassociated ALI may, at least partly, be mediated via Akt and $\mathrm{NF}-\kappa \mathrm{B}$ signaling pathways.

Due to the complexity of the chemical components of SSBE, the isolated component(s) responsible for contributing to the anti-inflammatory activity still need to be further studied and elucidated. The dosage and concentration of SSBE for the treatment of acute pancreatitis-associated ALI have not been reported previously. In previous studies, Sedum sarmentosum methanol in higher doses was associated with the best anti-inflammatory properties [28]. In our preliminary studies (data not shown), we had used a lower dosage of SSBE $(25 \mathrm{mg} / \mathrm{kg}, \mathrm{q} 12 \mathrm{~h})$, but the activity of serum amylase did not decrease and no change was noted in the pathological scores, so a higher dosage of SSBE $(100 \mathrm{mg} / \mathrm{kg}, \mathrm{q} 12 \mathrm{~h})$ was chosen in the present study.

\section{Conclusion}

In summary, we demonstrated that SSBE shows potent anti-inflammatory properties, and it is potentially capable of improving SAP-associated ALI, probably through the PI3-K/Akt signaling pathways by suppressing the NF- $\kappa \mathrm{B}$ activities. As a result, the production of proinflammatory cytokines in the lungs decreased, an effect beneficial in acute lung injury. These findings provide new insights into the role played by SSBE in acute pancreatitis-associated ALI, suggesting its potential value once the exact and most effective compounds have been identified.

\section{Conflicts of Interest}

The authors have declared no conflicts of interest in this work.

\section{Authors' Contributions}

Yuepeng Jin and Lewei Liu are equal contributors and co-first authors.

\section{Acknowledgments}

This study was supported by grants from China National Natural Science Foundation (no. 81370563), Zhejiang Provincial Natural Science Foundation of China (no. LQ13H160022), Bureau of Chinese Medicine of Zhejiang Province (2011ZA073), Bureau of Science and Technology of Wenzhou (H20110016), Excellent Youth Foundation of Zhejiang Provincial Natural Science (no. LR14H030001), Ministry of Health of China (no. WKJ2012-2-033), and Public Welfare Technology Application Research Project supported by Science Technology Department of Zhejiang province (no. 2012C23108).

\section{References}

[1] D. I. Heath, A. Cruickshank, M. Gudgeon, A. Jehanli, A. Shenkin, and C. W. Imrie, "Role of interleukin-6 in mediating the acute phase protein response and potential as an early means of severity assessment in acute pancreatitis," Gut, vol. 34, no. 1, pp. 41-45, 1993.

[2] P. Montravers, S. Chollet-Martin, J. P. Marmuse, M. A. Gougerot-Pocidalo, and J. M. Desmonts, "Lymphatic release of cytokines during acute lung injury complicating severe pancreatitis," American Journal of Respiratory and Critical Care Medicine, vol. 152, no. 5, pp. 1527-1533, 1995.

[3] A. C. De Beaux, A. S. Goldie, J. A. Ross, D. C. Carter, and K. C. H. Fearon, "Serum concentrations of inflammatory mediators related to organ failure in patients with acute pancreatitis," British Journal of Surgery, vol. 83, no. 3, pp. 349-353, 1996.

[4] M. Bhatia, M. Brady, S. Shokuhi, S. Christmas, J. P. Neoptolemos, and J. Slavin, "Inflammatory mediators in acute pancreatitis," The Journal of Pathology, vol. 190, no. 2, pp. 117-125, 2000.

[5] A. Buter, C. W. Imrie, C. R. Carter, S. Evans, and C. J. McKay, "Dynamic nature of early organ dysfunction determines outcome in acute pancreatitis," British Journal of Surgery, vol. 89, no. 3, pp. 298-302, 2002.

[6] M. Bhatia and S. Moochhala, "Role of inflammatory mediators in the pathophysiology of acute respiratory distress syndrome," The Journal of Pathology, vol. 202, no. 2, pp. 145-156, 2004.

[7] H. Zhang, P. Neuhöfer, L. Song et al., "IL-6 trans-signaling promotes pancreatitis-associated lung injury and lethality," The Journal of Clinical Investigation, vol. 123, no. 3, pp. 1019-1031, 2013.

[8] M. Surbatovic, K. Jovanovic, S. Radakovic, and N. Filipovic, "Pathophysiological aspects of severe acute pancreatitisassociated lung injury," Srpski Arhiv za Celokupno Lekarstvo, vol. 133, no. 1-2, pp. 76-81, 2005.

[9] C. W. Imrie, J. C. Ferguson, D. Murphy, and L. H. Blumgart, "Arterial hypoxia in acute pancreatitis," British Journal of Surgery, vol. 64, no. 3, pp. 185-188, 1977.

[10] W. Steinberg and S. Tenner, "Acute pancreatitis," The New England Journal of Medicine, vol. 330, no. 17, pp. 1198-1210, 1994.

[11] B. Gloor, C. A. Müller, M. Worni, M. E. Martignoni, W. Uhl, and M. W. Büchler, "Late mortality in patients with severe acute pancreatitis," British Journal of Surgery, vol. 88, no. 7, pp. 975979, 2001.

[12] S. Tenner, G. Sica, M. Hughes et al., "Relationship of necrosis to organ failure in severe acute pancreatitis," Gastroenterology, vol. 113, no. 3, pp. 899-903, 1997. 
[13] C. D. Johnson and M. Abu-Hilal, "Persistent organ failure during the first week as a marker of fatal outcome in acute pancreatitis," Gut, vol. 53, no. 9, pp. 1340-1344, 2004.

[14] H. Lei, W. Minghao, Y. Xiaonan, X. Ping, L. Ziqi, and X. Qing, "Acute lung injury in patients with severe acute pancreatitis," The Turkish Journal of Gastroenterology, vol. 24, no. 6, pp. 502507, 2013.

[15] S. Chooklin, "Pathogenic aspects of pulmonary complications in acute pancreatitis patients," Hepatobiliary \& Pancreatic Diseases International, vol. 8, no. 2, pp. 186-192, 2009.

[16] H.-K. Yum, J. Arcaroli, J. Kupfner et al., "Involvement of phosphoinositide 3-kinases in neutrophil activation and the development of acute lung injury," The Journal of Immunology, vol. 167, no. 11, pp. 6601-6608, 2001.

[17] I. Samuel, S. Zaheer, J. J. Nelson, M. A. Yorek, and A. Zaheer, "CCK-A receptor induction and p38MAPK and NF- $\kappa$ B activation in acute pancreatitis," Pancreatology, vol. 4, no. 1, pp. 49-56, 2004.

[18] M. Severgnini, S. Takahashi, L. M. Rozo et al., "Activation of the STAT pathway in acute lung injury," American Journal of Physiology-Lung Cellular and Molecular Physiology, vol. 286, no. 6, pp. L1282-L1292, 2004.

[19] S.-H. Kan, F. Huang, J. Tang, Y. Gao, and C.-L. Yu, "Role of intrapulmonary expression of inducible nitric oxide synthase gene and nuclear factor $\kappa \mathrm{b}$ activation in severe pancreatitisassociated lung injury," Inflammation, vol. 33, no. 5, pp. 287-294, 2010.

[20] N. Luo, Y. Zhu, Z. Zhang, H. Chen, and Y. Wang, "Clinical observation on the combined therapy of sitagliptin with insulin for patients with brittle diabetes," Zhong Nan Da Xue Xue Bao Yi Xue Ban, vol. 40, pp. 1089-1095, 2015.

[21] T. De Campos, J. Deree, and R. Coimbra, "From acute pancreatitis to end-organ injury: Mechanisms of acute lung injury," Surgical Infections, vol. 8, no. 1, pp. 107-120, 2007.

[22] H. Akbarshahi, A. H. Rosendahl, G. Westergren-Thorsson, and R. Andersson, "Acute lung injury in acute pancreatitis-a waiting the big leap," Respiratory Medicine, vol. 106, no. 9, pp. 1199-1210, 2012.

[23] Y. Chen, J. Wang, and D. Wan, "Determination of total flavonoids in three Sedum crude drugs by UV-Vis spectrophotometry," Pharmacognosy Magazine, vol. 6, no. 24, pp. 259-263, 2010.

[24] T. H. Kang, H. O. Pae, J. C. Yoo et al., "Antiproliferative effects of alkaloids from Sedum sarmentosum on murine and human hepatoma cell lines," Journal of Ethnopharmacology, vol. 70, no. 2, pp. 177-182, 2000.

[25] W.-L. Jiang, Y. Xu, S.-P. Zhang, H.-B. Zhu, and J. Hou, “Tricin 7-glucoside protects against experimental cerebral ischemia by reduction of NF- $\kappa \mathrm{B}$ and HMGB1 expression," European Journal of Pharmaceutical Sciences, vol. 45, no. 1-2, pp. 50-57, 2012.

[26] W. Dong, C. Xu, T. Cheng, and S. Zhou, "Complete chloroplast genome of Sedum sarmentosum and chloroplast genome evolution in Saxifragales," PLoS ONE, vol. 8, no. 10, Article ID e77965, 2013.

[27] T. Morikawa, Y. Zhang, S. Nakamura, H. Matsuda, O. Muraoka, and M. Yoshikawa, "Bioactive constituents from Chinese natural medicines. XXII. Absolute structures of new megastigmane glycosides, sedumosides E1, E 2, E3, F1, F2, and G, from Sedum sarmentosum (Crassulaceae)," Chemical \& Pharmaceutical Bulletin, vol. 55, no. 3, pp. 435-441, 2007.
[28] H.-J. Jung, H.-J. Kang, Y. S. Song, E.-H. Park, Y.-M. Kim, and C.-J. Lim, "Anti-inflammatory, anti-angiogenic and antinociceptive activities of Sedum sarmentosum extract," Journal of Ethnopharmacology, vol. 116, no. 1, pp. 138-143, 2008.

[29] Y. Bai, H. Lu, L. Hu, D. Hong, L. Ding, and B. Chen, "Effect of Sedum sarmentosum BUNGE extract on aristolochic acidinduced renal tubular epithelial cell injury," Journal of Pharmacological Sciences, vol. 124, no. 4, pp. 445-456, 2014.

[30] K. Ninomiya, T. Morikawa, Y. Zhang et al., "Bioactive constituents from Chinese natural medicines. XXIII.1 absolute structures of new megastigmane glycosides, sedumosides A4, $\mathrm{A} 5, \mathrm{~A} 6, \mathrm{H}$, and I, and hepatoprotective megastigmanes from Sedum sarmentosum," Chemical \& Pharmaceutical Bulletin, vol. 55, no. 8, pp. 1185-1191, 2007.

[31] M.-M. Wang, T. Zhang, L.-H. Yang et al., "Sedum sarmentosun bunge extraction ameliorated severe acute pancreatitis-induced lung injury: an experimental research," Zhongguo Zhong Xi Yi Jie He Za Zhi Zhongguo Zhongxiyi Jiehe Zazhi, vol. 35, no. 2, pp. 228-233, 2015.

[32] H. J. Aho, S. M.-L. Koskensalo, and T. J. Nevalainen, "Experimental pancreatitis in the rat: Sodium taurocholate-induced acute haemorrhagic pancreatitis," Scandinavian Journal of Gastroenterology, vol. 15, no. 4, pp. 411-416, 1980.

[33] J. Schmidt, D. W. Rattner, K. Lewandrowski et al., "A better model of acute pancreatitis for evaluating therapy," Annals of Surgery, vol. 215, no. 1, pp. 44-56, 1992.

[34] M. O. Osman, J. U. Kristensen, N. O. Jacobsen et al., "A monoclonal anti-interleukin 8 antibody (WS-4) inhibits cytokine response and acute lung injury in experimental severe acute necrotising pancreatitis in rabbits," Gut, vol. 43 , no. 2 , pp. $232-$ 239, 1998.

[35] A. S. Haqqani, J. K. Sandhu, and H. C. Birnboim, "A myeloperoxidase-specific assay based upon bromidedependent chemiluminescence of luminol," Analytical Biochemistry, vol. 273, no. 1, pp. 126-132, 1999.

[36] C. J. Shields, D. C. Winter, and H. P. Redmond, "Lung injury in acute pancreatitis: Mechanisms, prevention, and therapy," Current Opinion in Critical Care, vol. 8, no. 2, pp. 158-163, 2002.

[37] S. Wei, Q. Huang, J. Li et al., "Taurine attenuates liver injury by downregulating phosphorylated p38 MAPK of Kupffer cells in rats with severe acute pancreatitis," Inflammation, vol. 35, no. 2, pp. 690-701, 2012.

[38] J.-L. Frossard, A. Saluja, L. Bhagat et al., "The role of intercellular adhesion molecule 1 and neutrophils in acute pancreatitis and pancreatitis-associated lung injury," Gastroenterology, vol. 116, no. 3, pp. 694-701, 1999.

[39] D. Closa, L. Sabater, L. Fernández-Cruz, N. Prats, E. Gelpí, and J. Roselló-Catafau, "Activation of alveolar macrophages in lung injury associated with experimental acute pancreatitis is mediated by the liver," Annals of Surgery, vol. 229, no. 2, pp. 230236, 1999.

[40] C. Chen, S. Xu, W.-X. Wang et al., "Rosiglitazone attenuates the severity of sodium taurocholate-induced acute pancreatitis and pancreatitis-associated lung injury," Archives of Medical Research, vol. 40, no. 2, pp. 79-88, 2009.

[41] J.-D. Ren, Y.-J. Xing, K.-H. Fan et al., "Pharmacological blockade of the MaxiK channel attenuates experimental acute pancreatitis and associated lung injury in rats," International Immunopharmacology, vol. 21, no. 1, pp. 220-224, 2014.

[42] P. Chen, L. Huang, Y. Zhang, M. Qiao, W. Yao, and Y. Yuan, "The antagonist of the JAK-1/STAT-1 signaling pathway improves the 
severity of cerulein-stimulated pancreatic injury via inhibition of NF- $\kappa \mathrm{B}$ activity," International Journal of Molecular Medicine, vol. 27, no. 5, pp. 731-738, 2011.

[43] D. E. Williard, E. Twait, Z. Yuan, A. B. Carter, and I. Samuel, "Nuclear factor kappa B-dependent gene transcription in cholecystokinin- and tumor necrosis factor- $\alpha$-stimulated isolated acinar cells is regulated by p38 mitogen-activated protein kinase," The American Journal of Surgery, vol. 200, no. 2, pp. 283-290, 2010.

[44] Z. Sun, S. Dragon, A. Becker, and A. S. Gounni, "Leptin Inhibits Neutrophil Apoptosis in Children via ERK/NF- $\kappa$ B-Dependent Pathways," PLoS ONE, vol. 8, no. 1, Article ID e55249, 2013.

[45] E. Twait, D. E. Williard, and I. Samuel, "Dominant negative p38 mitogen-activated protein kinase expression inhibits NF$\kappa \mathrm{B}$ activation in AR42J cells," Pancreatology, vol. 10, no. 2-3, pp. 119-128, 2010.

[46] S. K. Manna and B. B. Aggarwal, "Wortmannin inhibits activation of nuclear transcription factors NF- $\kappa \mathrm{B}$ and activated protein-1 induced by lipopolysaccharide and phorbol ester," FEBS Letters, vol. 473, no. 1, pp. 113-118, 2000.

[47] K. Kim, C. Yang, A. Shin et al., "Mycobacterial heparin-binding hemagglutinin antigen activates inflammatory responses through PI3-K/Akt, NF- $\kappa \mathrm{B}$, and MAPK pathways," Immune Network, vol. 11, no. 2, pp. 123-133, 2011.

[48] S. A. Reddy, J. H. Huang, and W. S. Liao, "Phosphatidylinositol 3-kinase as a mediator of TNF-induced NF-kappa B activation," The Journal of Immunology, vol. 164, pp. 1355-1363, 2000.

[49] Y. Sailai, X. Yu, P. Baiheti, H. Tang, Y. Li, and M. Xu, "Influence of nuclear factor $\kappa \mathrm{b}$ activation on inflammatory mediators of alveolar macrophages in rats with acute necrotizing pancreatitis," Journal of Investigative Medicine, vol. 58, no. 1, pp. 38-42, 2010.

[50] A. Satoh, T. Shimosegawa, M. Fujita et al., "Inhibition of nuclear factor- $\kappa \mathrm{B}$ activation improves the survival of rats with taurocholate pancreatitis," Gut, vol. 44, no. 2, pp. 253-258, 1999. 

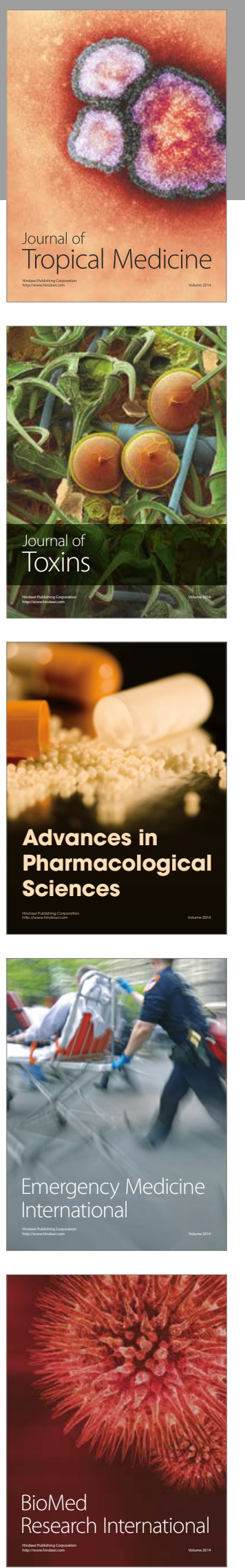
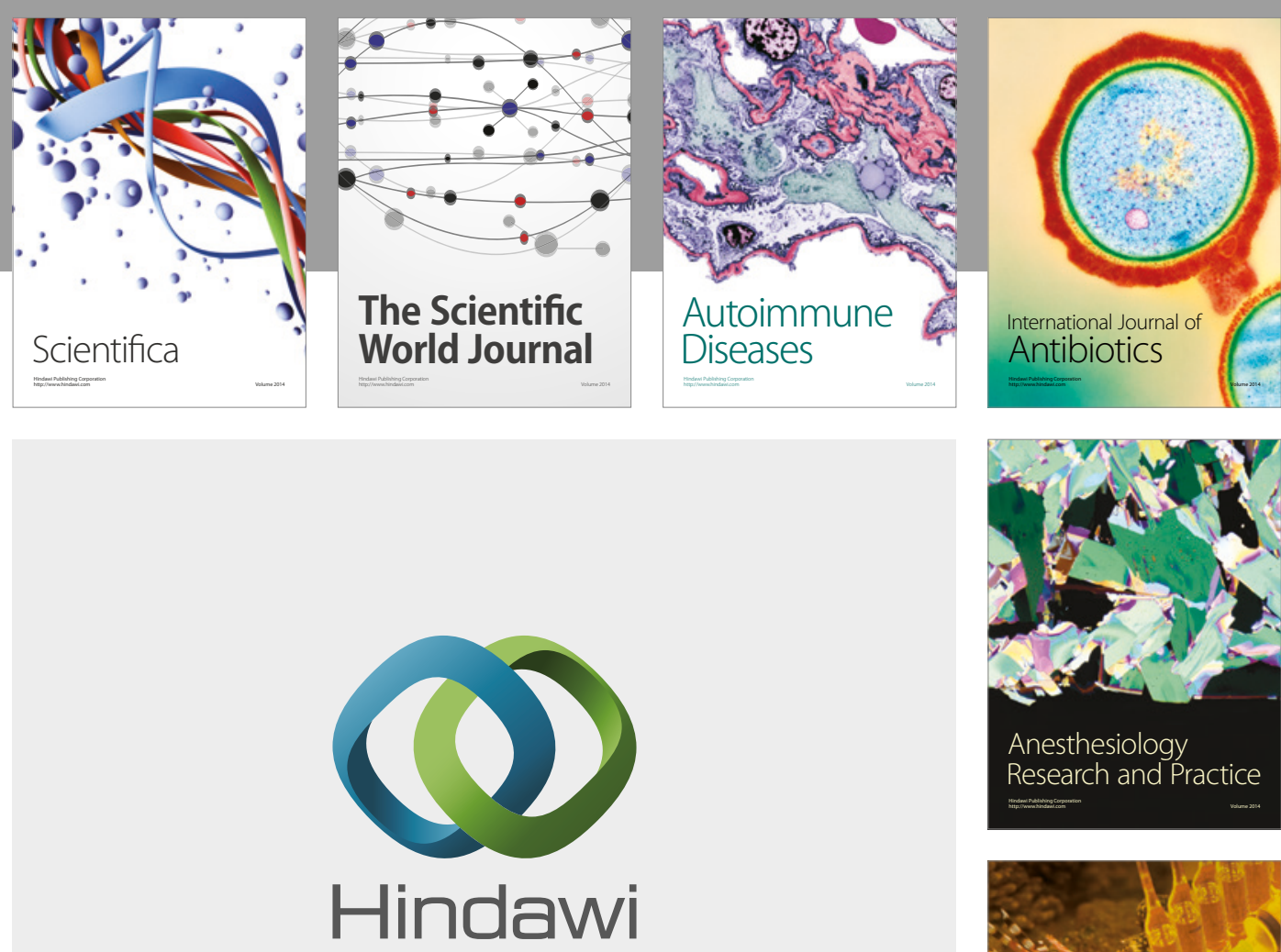

Submit your manuscripts at

https://www.hindawi.com
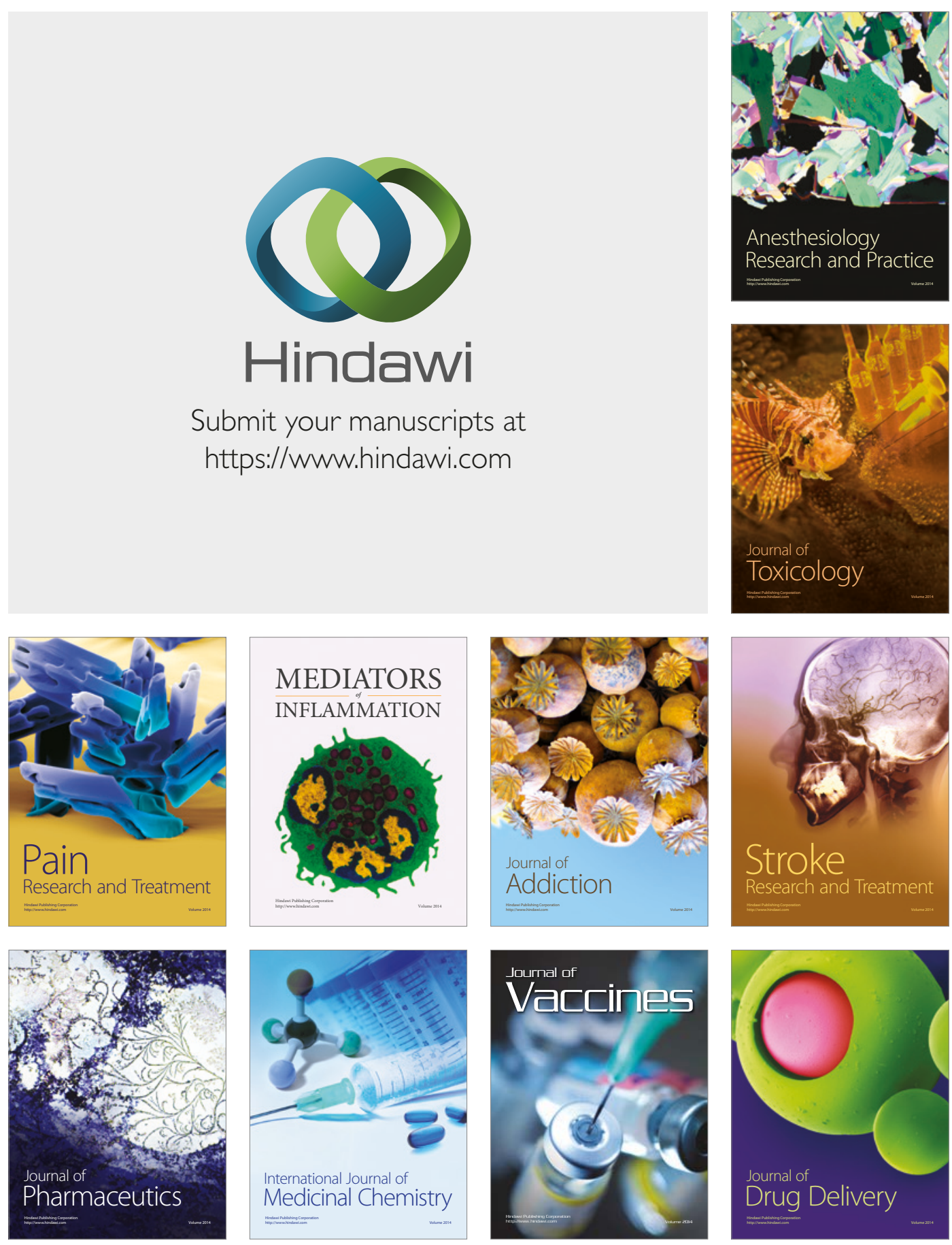